1 Title: A novel surfactant protein is associated with extrapulmonary respiration in

2 lungless salamanders

4 Short title: Novel surfactant protein in salamanders

6 Authors: Zachary R. Lewis, ${ }^{1,2^{*}}$ Jorge A. Dorantes, ${ }^{1,3}$ James Hanken $^{1}$

8 Institutions:

$9{ }^{1}$ Department of Organismic and Evolutionary Biology and Museum of

10 Comparative Zoology, Harvard University, Cambridge, MA, USA, 02138

112 Present address: Department of Ecology and Evolutionary Biology, Yale

12 University, New Haven, CT, USA, 06511

$13{ }^{3}$ Present address: Universidad Autónoma de Guadalajara, Facultad de Medicina,

14 Guadalajara, Jalisco, C.P. 44100, México

15

16 * To whom correspondence should be addressed

$17 \quad$ E-mail: zrlewis@gmail.com

18 Address: 165 Prospect St, New Haven, CT, 06511

19 Telephone: 1-206-920-3567

20

21 Keywords: Salamander, respiration, gene duplication, molecular evolution,

22 surfactant, plethodontid 
23 Abstract: Numerous physiological and morphological adaptations were achieved

24 during the transition to lungless respiration following evolutionary lung loss in

25 plethodontid salamanders, including those that enable efficient gas exchange

26 across extrapulmonary tissue. However, the molecular basis of these adaptations

27 is unknown. Here we show that lungless salamanders express in the skin and

28 buccal cavity - the principal sites of respiratory gas exchange in these species-

29 a novel paralog of the gene Surfactant-Associated Protein C (SFTPC), which is a

30 critical component of pulmonary surfactant expressed exclusively in the lung in

31 other vertebrates. The paralogous gene appears to be found only in

32 salamanders, but, similar to SFTPC, in lunged salamanders it is expressed only

33 in the lung. This heterotopic gene expression, combined with predictions from

34 structural modeling and respiratory tissue ultrastructure, suggest that lungless

35 salamanders produce pulmonary surfactant-like secretions outside the lungs and

36 that the novel paralog of SFTPC might facilitate extrapulmonary respiration in the

37 absence of lungs. Heterotopic expression of the SFTPC paralog may have

38 contributed to the remarkable evolutionary radiation of lungless salamanders,

39 which account for more than two thirds of urodele species alive today. 
40 Introduction: Most amphibians must confront the challenges of respiring both in

41 water and on land. To do so, they utilize numerous gas exchange surfaces

42 including the lungs, gills, integument and buccopharyngeal mucosa, which are

43 employed to varying extents depending on species and life-history stage. In adult

44 salamanders, for example, the integument may be responsible for $50 \%$ or more

45 of oxygen uptake [1,2]. Lability in sites of gas exchange is especially critical for

46 metamorphosing species, which face different respiratory demands in air and

47 water. Little is known, however, about the molecular mechanisms that enable the

48 ontogenetic and evolutionary transitions from aquatic to aerial respiration. The

49 mechanism of aerial respiration is even more enigmatic in lungless species,

50 which rely entirely on extrapulmonary sites of respiration [1-3]. The family

51 Plethodontidae includes more than two thirds of all living salamander species;

52 most are fully terrestrial, and all adults lack lungs. Respiration takes place solely

53 across the integument and buccopharyngeal mucosa, and also across the gills in

54 aquatic larval forms, when present. Lunglessness is not unique to

55 plethodontids - it has evolved several times in other amphibians, including

56 salamanders, frogs and caecilians [4] —but its adaptive significance is unresolved

$57 \quad[5,6]$.

58

59 How lungless salamanders are able to satisfy metabolic demands for oxygen is a

60 topic of considerable interest. In theory, lunglessness limits thermal tolerance

61 and maximum body size, yet lungless salamanders paradoxically occupy diverse

62 thermal environments and attain relatively large body sizes. Plethodontids 
63 possess highly vascularized skin and buccopharyngeal mucosa, which may

64 compensate for the loss of pulmonary respiration [1,7-9]. The buccopharyngeal

65 membranes, in particular, may function as an adaptive respiratory surface that

66 facilitates gas exchange, as evidenced by increased oscillation of the floor of the

67 buccal cavity under hypoxia, high temperature, or activity, which presumably

68 serves to draw more air into the mouth $[1,7,10]$. Selection for efficient

69 extrapulmonary respiration may have played a major role in the adaptive

70 radiation of terrestrial plethodontids [1]. Indeed, the evolution of highly efficient

71 cutaneous and buccopharyngeal respiration is believed to have freed

72 plethodontids from the ontogenetic and functional constraints associated with the

73 use of a buccal pump for pulmonary ventilation, thereby enabling them to occupy

74 diverse habitats and evolve ballistic tongue projection $[2,11,12]$.

76 To identify the molecular adaptations that might facilitate lungless respiration, we

77 investigated the expression of a crucial pulmonary surfactant-associated protein

78 in plethodontid salamanders. Proper lung function requires pulmonary surfactant,

79 a complex and evolutionarily variable mix of molecules that facilitate mucous

80 spreading and lung compliance and improve oxygen diffusion [13-15].

81 Surfactant-associated protein C (SFTPC) is a hydrophobic protein found in

82 pulmonary surfactant that localizes to the lung's air-liquid interface. It reduces

83 surface tension by aiding the adsorption and distribution of lipids within

84 pulmonary surfactant and specifically enhances oxygen diffusion $[14,16,17]$.

85 SFTPC also regulates production and turnover of phosphatidylcholine, a major 
86 component of pulmonary surfactant, and it limits the thickness of the hypophase,

87 the liquid layer that lines the lung's inner surface [18-20]. Mucous layer thickness

88 greatly impacts gas exchange between the environment and the blood supply

89 [21]. Additionally, oxygen uptake is enhanced by the presence of surfactant in the

90 hypophase, likely due to convective effects that facilitate mixing of oxygen and

91 mucous or increased rate of oxygen trafficking [15,22]. The expression of SFTPC

92 is highly conserved among tetrapods: all species evaluated previously express

93 SFTPC exclusively in the lungs [23-25] (and Supplementary Text).

95 Results and Discussion: Despite lacking lungs as adults, plethodontid

96 salamanders express SFTPC (Fig. S1). Due to the consistent restriction of

97 SFTPC expression to the lungs and to SFTPC's conserved role across tetrapods,

98 we compared SFTPC expression between lungless and lunged salamanders.

99 Surprisingly, several species of salamanders express two transcripts with high

100 sequence identity to annotated SFTPC sequences (Fig. S1a, b). Both transcripts

101 exclusively match SFTPC within the NCBI nucleotide collection database, but

102 one possesses higher sequence similarity to amniote and frog SFTPC. We

103 denote the transcript with lower similarity SFTPC-like. We did not find SFTPC-

104 like within vertebrate genomes or transcriptomes outside of salamanders.

105 Phylogenetic analyses support the hypothesis that SFTPC-like represents a

106 previously undescribed salamander-specific paralog of the highly conserved

107 lung-specific gene, SFTPC (Figs. S1, S3; Supplementary Text). SFTPC-like may 
108 maintain or partially maintain the characteristic hydrophobic alpha-helical

109 configuration of the SFTPC mature peptide [16] (Fig. S1c).

111 Numerous studies of tetrapods localize SFTPC exclusively to the lungs [23-25].

112 SFTPC and SFTPC-like in the lunged salamander Ambystoma mexicanum

113 match this highly conserved pattern (Fig. 1). As visualized by in situ hybridization,

114 SFTPC and SFTPC-like staining is only observed in the extremely squamous

115 alveolar epithelial cells lining the lungs and trachea (Figs. 1, S5, S6). SFTPC-like

116 expression, however, is lower than SFTPC and the genes are expressed at

117 different times: SFTPC-like is low or non-existent before hatching, whereas

118 SFTPC is expressed beginning in embryos immediately following the formation of

119 the laryngotracheal groove, a ventral outpocketing of the foregut that precedes

120 lung outgrowth (Fig. 1a, b), and continuing into adulthood (Fig. 1d).

122 In contrast, SFTPC-like is expressed dynamically in lungless salamanders. In

123 embryos and early larvae of Desmognathus fuscus, a metamorphosing species,

124 SFTPC-like is expressed throughout much of the integument, with reduced

125 staining on the dorsal (internal) surface of the operculum (gill covering) and in the

126 limbs (Fig. 2a-h). Expression begins to diminish in the integument immediately

127 before metamorphosis, but at the same time it expands to the buccopharyngeal

128 mucosa (oral epithelium) (Fig. 2i-l). Integumentary expression at this stage is

129 patchy: remaining SFTPC-like-positive cells are displaced towards the apical

130 surface and display an irregular morphology (Fig. 2i, k). Cessation of 
131 integumentary expression of SFTPC-like coincides with several metamorphic

132 transitions, but especially molting [26], when the integument is profoundly

133 remodeled from a simple stratified epithelium to a thickened pseudostratified

134 tissue rich in acinous glands (Fig. S4, Fig. 2i, k).

135

136 Immediately following metamorphosis, expression is absent from the integument

137 and restricted to the buccopharyngeal mucosa (Fig. 2m-r). In adults, SFTPC-like

138 is expressed in the buccal cavity and adjacent pharynx (Fig. $2 \mathrm{~m}-\mathrm{r}$ ): it is confined

139 to oral mucosa, with a strict boundary at the marginal teeth. SFTPC-like is not

140 expressed along the vomerine bones (near the internal nares) or in the dorsal

141 midline of the tongue, although it is strongly expressed along the tongue margin

142 (Fig. 2m, o). Additional data from immunohistochemistry and mass spectroscopy

143 are needed to determine if SFTPC-like transcripts are translated and whether this

144 protein is then processed and secreted in a similar fashion to SFTPC in the lung.

146 Unlike SFTPC-like, SFTPC is expressed at an extremely low level in embryos of

147 lungless species, which develop a transient lung rudiment [27]. The SFTPC

148 transcript detected from transcriptome sequencing of the lung rudiment of

149 Plethodon cinereus (Supplemental Data File 1) could not be cloned from either $P$.

150 cinereus or $D$. fuscus, nor was it found in adult plethodontid transcriptomes. This

151 suggests that SFTPC expression is inhibited by lung loss in lungless species,

152 with the exception of SFTPC expression at certain embryonic stages in the

153 presumptive lung region. 
155 The larval integument of Desmognathus fuscus displays pronounced secretory 156 activity (Fig. 3a-d). The outer layer-the stratum corneum-is a protective layer

157 composed of anuclear keratinized cells. It displays an extremely high level of

158 secretory activity evidenced by the near universal distribution of bilamellar

159 secretory vesicles along its superficial surface (Fig. 3a, "SV"). Just basal to the

160 stratum corneum is a layer of secretory cells, which are heavily vacuolated at

161 their apical extent. The stratum corneum and the layer of secretory cells are not

162 separated by a cell membrane, but a dark and consistent division appears

163 between them (Fig. 3b). Bilamellar secretory vesicles virtually identical to those

164 observed on the stratum corneum of $D$. fuscus are secreted from alveolar

165 epithelial cells in the lung of Ambystoma mexicanum but are not present in its

166 integument (Fig. 3e, g, h; Fig. S6, "SV").

167

168 Pulmonary surfactant is trafficked in lamellar bodies in alveolar epithelial cells.

169 These lamellar bodies are distinct from other ultrastructural lamellar elements in

170 that they are large in diameter and spherical in shape [28-30]. Furthermore,

171 these lamellar bodies are distinct from the bilamellar structures identified on the

172 surface of the integument, in that they have many lamellae. The larval

173 integument of $D$. fuscus contains large $(0.5-0.75 \mu \mathrm{m}$ diameter $)$, spherical

174 lamellar bodies (Fig. 3c, d, "LB") that closely resemble those found in alveolar

175 epithelial cells, which otherwise are known only from the lungs of other

176 tetrapods.. Secretory activity and the presence of these distinctive lamellar 
177 bodies strongly suggest that $D$. fuscus produces surfactant in extrapulmonary

178 sites of gas exchange, which correspond to sites of SFTPC-like expression.

180 Despite the lung- and trachea-specific expression of SFTPC and SFTPC-like in

181 A. mexicanum revealed by in situ hybridization and the numerous reports of lung-

182 specific expression of SFTPC in mammals (Supplementary text), recently

183 published transcriptomes of $A$. mexicanum purport to map low numbers of

184 SFTPC and SFTPC-like reads to several tissues, including blood vessels, bone,

185 heart, regenerating limbs, and mixed stages of whole embryos [31]. Therefore,

186 SFTPC and SFTPC-like may not be entirely lung-specific transcripts in lunged

187 salamanders. Additional studies are needed, however, to evaluate the alternative

188 interpretation that contamination, mapping or assembly issues might have

189 yielded spuriously mapped reads.

190

191 Passive diffusion across a tissue layer, as occurs during cutaneous respiration, is

192 a function of several variables. These include the size (area) of the surface over

193 which gas exchange occurs and the thickness of the barrier between the

194 underlying blood supply and the environment [3]. Barrier thickness depends

195 mainly on the distance between the environment and the blood supply, but also

196 on the thickness of the mucous layer between the environment and respiratory

197 tissue. Diffusivity of mucus is about $30 \%$ lower than water [21]. Reduction of

198 surface tension by pulmonary surfactant helps maintain a thin layer of airway

199 surface liquid [20] and increases convection within the mucous, which together 
200 result in increased oxygen uptake [22]. SFTPC indirectly influences mucous layer

201 thickness in the lung by regulating the production of phosphatidylcholine [18].

202 Pulmonary surfactant aids oxygen transport across the air-liquid interface, and

203 hydrophobic surfactant proteins increase the rate of oxygen diffusion twofold over

204 surfactant lipid alone [15,17]. SFTPC-like may facilitate respiration through a

205 reduction of effective barrier thickness or an increase in diffusivity of the mucus

206 layer. Pulmonary surfactant also plays non-respiratory roles, including facilitation

207 of mucus spreading, innate immune defense, anti-edema agent, hydrostatic gas

208 exchange, and preventing adhesion of lung surfaces when the lungs deflate

$209[13,32,33]$. It is possible that extrapulmonary surfactant produced in

210 Desmognathus fuscus is performing one or more of these functions instead of, or

211 in addition to, facilitating gas exchange.

213 Spatial and temporal expression of SFTPC-like and the ultrastructure of the

214 associated integument suggest that, following SFTPC-gene duplication, SFTPC-

215 like became neofunctionalized for extrapulmonary respiration in lungless

216 salamanders. Sequence and structural conservation of SFTPC-like and SFTPC

217 suggests that the two proteins function similarly (Fig. S1). However, to confirm

218 neofunctionalization requires a more detailed functional characterization of

219 SFTPC-like. This may include determining with increased phylogenetic and

220 technical precision how expression of SFTPC-like has evolved in salamanders,

221 proteomic characterization of skin and buccopharyngeal secretions, and 
222 assessment of whether SFTPC-like displays surface activity or aids gas

223 exchange.

224

225 In metamorphosing species such as Desmognathus fuscus, respiratory and fluid-

226 retention demands shift dramatically upon the transition from aquatic to terrestrial

227 habitats [1]. Cutaneous water loss becomes a critical liability, but reduced skin

228 permeability hinders cutaneous gas exchange. To counter this limitation,

229 terrestrial plethodontids show increased reliance on buccopharyngeal respiration

230 [1]. Ontogenetic shift of SFTPC-like from the skin to the buccopharyngeal cavity

231 during metamorphosis (Fig. 2) correlates with the transition from aquatic to aerial

232 respiration; SFTPC-like is expressed at the preferential sites of gas exchange at

233 each life-history stage [1]. However, it is also possible that instead of playing a

234 direct role in facilitating gas exchange, extrapulmonary surfactant balances fluid

235 retention and respiratory demands by aiding fluid uptake from the mucus. Such a

236 role would be consistent with the proposed anti-edema properties of surfactant

237 within the lungs [13].

239 Gene duplication is increasingly recognized as a driving force of evolutionary

240 innovation [34]. While gene duplication does not always lead to functional

241 divergence $[35,36]$, regulatory changes in duplicated genes, such as altered

242 expression sites, may enable the evolution of novel traits in individual lineages.

243 Many studies of the evolutionary phenomenon of adaptive radiation have

244 emphasized morphological traits whose appearance in particular lineages 
245 promote phylogenetic and ecological diversification [37]. We propose that such

246 morphological traits, or key adaptations, work in concert with novel and

247 functionally significant molecular features to enhance evolutionary success, and

248 that such instances of concerted evolution are more widespread than is currently

249 recognized.

250

251 In plethodontid salamanders, it is possible that the combination of morphological

252 adaptations $[7,9,38]$ and novel deployment of a critical surfactant protein enables

253 efficient extrapulmonary respiration via the buccopharynx and integument.

254 Conserved expression of SFTPC-like in lunged salamanders relative to SFTPC

255 may be due to dosage-sharing between SFTPC and SFTPC-like, which

256 constrains tolerable mutations in SFTPC-like gene regulation [35]. Indeed, lung

257 loss may have resulted in relaxed stabilizing selection for SFTPC-like gene

258 regulation, thereby enabling the evolution of novel expression patterns. Greater

259 understanding of the evolution and function of SFTPC-like in additional

260 salamander species will yield a more complete picture of the evolution and

261 consequences of lung loss, while functional studies of SFTPC-like promise to

262 reveal whether this novel pulmonary surfactant protein plays similar roles to

263 SFTPC or has potential therapeutic applications. Given the convergent evolution

264 of lung loss in several amphibian lineages, it will be interesting to investigate the

265 molecular physiology of other lungless taxa. Neofunctionalization of SFTPC-like

266 may represent an additional mechanism by which plethodontid salamanders

267 have become one of the most speciose and geographically widespread clades of 
268 vertebrates on earth, despite the theoretical limitations on thermal tolerance and

269 body size imposed by lunglessness.

270

271 Materials and Methods:

272 Animal husbandry

273 All animal protocols were reviewed and approved by Harvard's Institutional

274 Animal Care and use Committee (protocol 99-09). Desmognathus fuscus

275 (Northern dusky salamander) embryos were field-collected from the following two

276 localities under Massachusetts Department of Fish and Wildlife collection permits

277 080.11SCRA (2012), 027.13SCRA (2013), 083.14SCRA (2014), and

278 022.15SCRA (2015) and appropriate local permits: Ashfield, Mass. (42.483111, -

279 72.761263) and Mass Audubon Wachusett Meadows Preserve (42.450922, -

$28071.913009)$. Adults were collected from Willard Brook State Forest (42.671606, -

281 71.776156). Plethodon cinereus (Eastern red-backed salamander) embryos were

282 field collected from Willard Brook State Forest (42.671606, -71.776156).

283 Desmognathus fuscus embryos were maintained at $15^{\circ} \mathrm{C}$ in $0.1 \mathrm{x}$ Marc's Modified

284 Ringer solution (MMR; $0.01 \mathrm{M} \mathrm{NaCl}, 0.2 \mathrm{mM} \mathrm{KCl}, 0.1 \mathrm{mM} \mathrm{MgSO}_{4}, 0.2 \mathrm{mM} \mathrm{CaCl}_{2}$,

$285 \quad 0.5 \mathrm{mM}$ HEPES pH 7.4). Following hatching, larvae were fed Artemia spp. and

286 maintained at $17-20^{\circ} \mathrm{C}$ until they metamorphosed at approximately seven

287 months post-hatching. Older larvae were hand-fed blood worms. Embryos and

288 larvae were sampled at intermediate stages from embryogenesis until 3-5 days

289 post-metamorphosis and fixed overnight in MEMFA (0.1 M MOPS pH 7.4, 2 mM

290 EGTA, $1 \mathrm{mM} \mathrm{MgSO}_{4}, 3.7 \%$ formaldehyde) at $4^{\circ} \mathrm{C}$, then dehydrated and stored at 
$291-20^{\circ} \mathrm{C}$ in $100 \%$ methanol. Adults were fixed in a similar manner immediately upon

292 collection.

293 Ambystoma mexicanum (Mexican axolotl) embryos were obtained from the

294 Ambystoma Genetic Stock Center, University of Kentucky, and maintained in

$29520 \%$ Holtfreter solution at $17^{\circ} \mathrm{C}$. Larvae were raised similarly to larval

296 Desmognathus fuscus. Fixation was performed as described above.

297 Ambystoma mexicanum were staged according to [39,40]. Desmognathus fuscus

298 embryos were staged using a staging table derived for Plethodon cinereus, as

299 their developmental timing and morphology are grossly similar [41].

300 PCR

301 Embryonic cDNA from Desmognathus fuscus, Plethodon cinereus, and

302 Ambystoma mexicanum was used to clone the gene SFTPC-like. RNA was

303 isolated from homogenates of whole animals at a variety of embryonic stages

304 using TRIzol Reagent (Invitrogen/Thermo Fisher Scientific, Grand Island, N.Y.)

305 and reverse-transcribed to cDNA using iScript reverse transcriptase (BioRad,

306 Hercules, Calif.). The gene SFTPC was cloned from A. mexicanum and repeated

307 attempts were made to clone SFTPC from plethodontids. Degenerate and non-

308 degenerate PCR primers were used (Table S1).

309 Primers were designed based on alignment of SFTPC sequences from

310 Desmognathus fuscus, Xenopus laevis, $X$. tropicalis, Anolis carolinensis,

311 Neovison vison, Bos taurus, Monodelphis domesticus, and Homo sapiens. All 
312 sequences but one were obtained from GenBank; the $D$. fuscus sequence was

313 kindly provided by Dr. David Weisrock.

\section{Transcriptome assembly}

315 Transcriptomes for Plethodon cinereus and Ambystoma mexicanum were

316 prepared from microdissected tissue from pharyngeal endoderm and mesoderm

317 of embryos and from the lung of a juvenile $A$. mexicanum. Total RNA was utilized

318 for library preparation by using the IntegenX PrepX RNA-Seq Library Kit

319 (IntegenX, Pleasanton, Calif.) on an Apollo 324 robotic sample preparation

320 system (WaferGen Biosystems, Fremont, Calif.), closely following kit instructions.

321 Agencourt Ampure XP beads were used for magnetic purification steps

322 (Beckman Coulter, Indianapolis, Ind.). Beads were kept at room temperature for

32315 min before starting block setup. Beads were added last to the block, after a

$324 \quad 30$-sec vortex to fully resuspend them.

325 Following cDNA synthesis, the concentration of samples was assessed by using

326 a Qubit 1.0 fluorometer (Invitrogen/Thermo Fisher Scientific, Grand Island, N.Y.),

327 high-sensitivity dsDNA reagents (Molecular Probes/Thermo Fisher Scientific,

328 Grand Island, N.Y.), and Qubit Assay Tubes (Invitrogen). Samples were diluted

329 to $20 \mu \mathrm{g} / \mathrm{ml}$ and then sheared on a Covaris S220 Focused ultrasonicator

330 (Covaris, Woburn, Mass.) using a 72-sec protocol and targeting 220/320 bp

331 output. TapeStation HS D1K tape (Agilent) was used to examine sheared DNA

332 for optimal size range. BIOO Scientific NEXTflex DNA barcodes (\#514102,

333 Austin, Tex.) were diluted to $5 \mu \mathrm{m}$ and used in the IntegenX PrepX DNA Library

334 ILM prep kit (\#P003279, Pleasanton, Calif.). Library prep was performed on the 
335 Apollo 324 using the kit manufacturer's precise instructions. 5- $\mu$ l aliquots of $\sim 2-$

$336 \mu \mathrm{g} / \mathrm{ml}$ samples were then subjected to four PCR amplification cycles by using

337 NEB Next Master Mix (\#M0541S, NEB, Ipswich, Mass.) and NEXTflex Primer

338 Mix (BIOO Scientific) and the following cycle conditions: denaturation at $98^{\circ} \mathrm{C}$ for

$339120 \mathrm{sec} ; 5$ cycles of $98^{\circ} \mathrm{C}$ for $30 \mathrm{sec}, 6^{\circ} \mathrm{C}$ for $30 \mathrm{sec}$, and $72^{\circ} \mathrm{C}$ for $60 \mathrm{sec}$; and

340 final extension for $5 \mathrm{~min}$ at $72^{\circ} \mathrm{C}$. The Agilent Apollo 324 was used for cleanup of

341 PCR samples using the built-in PCR cleanup protocol and Agencourt Ampure XP

342 beads. Libraries were analyzed with Qubit 1.0, TapeStation and qPCR to assess

343 library concentration, size and quality. Samples were each diluted to $0.29 \mathrm{nM}$

344 concentration and then pooled. Two lanes of $2 \times 150$ bp Illumina HiSeq 2500

345 Rapid Run RNA-sequencing (Illumina, San Diego, Calif.) yielded a total 232.4

346 reads that passed filter.

347 Sequenced reads were trimmed with Trimmomatic [42] and concatenated.

348 Ribosomal rRNA reads were removed by using Bowtie [43] and a custom

349 database of known rRNA sequences for each species. Transcriptomes were

350 assembled de novo using Trinity $[44,45]$. BLAST databases were created from

351 the de novo assemblies and used to identify SFTPC and SFTPC-like sequences.

\section{SFTPC phylogeny}

353 SFTPC sequences were identified through BLASTX, TBLASTN and TBLASTX

354 searches of sequenced transcriptomes from this study (Plethodon cinereus and

355 Ambystoma mexicanum) as well as from the transcriptomes listed in Table S2.

356 Sequence identifiers and corresponding sequence data are provided as

357 Supplemental Data File 1. 
358 SFTPC sequences from annotated genomes were also taken from NCBI and

359 ENSEMBL (Supplemental Data File 1). Outgroup proteins were selected based

360 on previous phylogenies of SFTPC $[46,47]$. Predicted amino acid sequences

361 were generated from all nucleotide sequences. Multiple sequence alignment was

362 performed using PRANK [48]; resulting alignments were visually inspected

363 (Supplemental Data File 2). ProtTest was used to identify an appropriate amino

364 acid substitution model [49]. The optimal amino acid substitution model was

$365 \mathrm{JTT}+\mathrm{G}[50]$, as judged by AIC. Subsequently, 95\% maximum clade credibility

366 gene trees were reconstructed in MrBayes (v3.2.6) [51] using Markov chain

367 Monte Carlo analysis with one million generations sampled every 100

368 generations and a relative burn-in of $25 \%$. Convergence of the posterior

369 probabilities was assessed by examining output statistics, including the potential

370 scale reduction factor, which equaled or exceeded 1.000 .

371 A phylogeny was also constructed in RAxML (v8.2.9) [52] by using 1000

372 bootstrap replicates and the aforementioned amino acid substitution model. Tree

373 topology was concordant with the Bayesian tree generated in Mr. Bayes.

374 JalView was used to generate the multiple sequence alignment image [53].

375 PHYLDOG [54] was used to estimate gene duplication of SFTPC. A guide tree

376 was constructed using NCBI taxonomy for major groups and [55] for amphibian

377 relationships (Fig. S2). Topology optimization was not used.

\section{In situ hybridization}


379 Embryos were fixed overnight in $4 \%$ paraformaldehyde (PFA) or MEMFA at $4^{\circ} \mathrm{C}$, 380 dehydrated and stored in $70 \%$ or $100 \% \mathrm{MeOH}$ at $-20^{\circ} \mathrm{C}$. Wholemount mRNA in 381 situ hybridization (ISH) was performed by rehydrating samples, which were then

382 treated with $5-10 \mu \mathrm{g} / \mathrm{ml}$ proteinase $\mathrm{K}$ for $30-60 \mathrm{~min}$, washed with PBTw (137 mM $383 \mathrm{NaCl}, 2.7 \mathrm{mM} \mathrm{KCl}, 10 \mathrm{mM} \mathrm{Na} 2 \mathrm{HPO}_{4}, 1.8 \mathrm{mM} \mathrm{KH}_{2} \mathrm{PO}_{4}$ and 0.2\% Tween-20),

384 post-fixed in 4\% PFA, washed with PBTw, and pre-hybridized in hybridization 385 buffer for $2 \mathrm{hr}$ at $65^{\circ} \mathrm{C}$ (hybridization buffer: $50 \%$ formamide, $5 x \mathrm{SSC}, 0.1 \mathrm{mg} / \mathrm{ml}$ 386 heparin, $1 \times$ Denhardt solution, $0.01 \%$ CHAPS, $0.2 \mathrm{mg} / \mathrm{ml}$ tRNA and $0.1 \%$ Tween387 20; all solutions were RNase-free). DIG-labeled riboprobes were diluted 388 approximately $1: 40$ in hybridization buffer, denatured at $85^{\circ} \mathrm{C}$ for $10 \mathrm{~min}$, and 389 then added to specimens. Hybridization was carried out overnight at $65^{\circ} \mathrm{C}$. 390 Posthybridization washes were performed with a solution of $50 \%$ formamide, $5 x$ 391 SSC and $0.2 \%$ Tween- 20 at $65^{\circ} \mathrm{C}$ for eight changes of 30 min each. Specimens 392 were washed with maleic acid buffer plus $0.2 \%$ Tween-20 (MABT) prior to 393 blocking and antibody incubation. Antibody block solution included $20 \%$ heat394 inactivated sheep serum and 2\% blocking reagent (Roche, Penzberg, Germany) 395 in MABT. Samples were incubated overnight at $4^{\circ} \mathrm{C}$ with 1:2500 anti-DIG-AP Fab 396 fragments (Roche) diluted in blocking solution. Extensive washes with MABT 397 were performed prior to color development using BM-Purple (Roche) or 398 NBT/BCIP (Sigma, St. Louis, Mo.). Color development occurred over several 399 hours. Embryos were then embedded for cryosectioning at 14-16 $\mu \mathrm{m}$ thickness.

400 Photographs were taken using a Leica DMRE microscope (Wetzlar, Germany) 401 equipped with a QImaging Retiga 2000r camera and a QImaging RGB slider 
402 (Model: RGB-HM-S-IR; Surrey, Canada) and Volocity 6.0 software (PerkinEImer, 403 Waltham, Mass.).

\section{Structure models}

405 An experimentally determined protein data bank (PDB) model for porcine SFTPC 406 [16] was downloaded from the Research Collaboratory for Structural

407 Bioinformatics PDB. The secondary and supersecondary structure of

408 Desmognathus fuscus SFTPC-like was predicted using Quark $A b$ initio Protein

409 Structure Prediction [56]. The N- and C-terminal extent of the Desmognathus

410 SFTPC-like sequence was chosen based on alignment with mature forms of

411 SFTPC found in mammals. Protein structure prediction was also performed with

412 I-TASSER [57].

413 A structure model for D. fuscus SFTPC-like was also predicted in SWISS-

414 MODEL [58] using the molecular structure derived by Johansson et al. [16] as a

415 template. The PDB files for each SFTPC-like model were imported into PyMol

416 (Schrödinger) and aligned with the SFTPC model to graphically illustrate

417 structural similarities.

\section{Transmission electron microscopy}

419 Two 24-mm (total length) Desmognathus fuscus larvae were euthanized and

420 decapitated. Specimens were then dissected in fixative $(2.5 \%$ glutaraldehyde and

$4212 \%$ paraformaldehyde in 0.1 M HEPES; the aldehydes were free of alcohol

422 stabilizers). The head was cut into three 1-mm sagittal sections. An 18-cm adult

423 Ambystoma mexicanum was euthanized and then dissected in fixative. Samples 
424 of the gular skin from the ventral head, the oral epithelium and the lungs were

425 trimmed to 1-mm-thick pieces in fixative and fixed as above.

426 The samples were left in fixative for $3 \mathrm{~d}$ and then washed twice quickly with $0.1 \mathrm{M}$

427 HEPES and three times for 5 min each with Milli-Q $\mathrm{H}_{2} \mathrm{O}\left(\mathrm{mqH}_{2} \mathrm{O}\right)$. Next, samples

428 were fixed for $24 \mathrm{hr}$ at $4^{\circ} \mathrm{C}$ in aqueous $1 \%$ osmium tetroxide, followed by five

429 washes in $\mathrm{mqH}_{2} \mathrm{O}$ for 5 min each. Subsequently, specimens were stained with

$4302 \%$ uranyl acetate (EMS, Hatfield, Pa.) overnight at $4^{\circ} \mathrm{C}$, then washed two times

431 for 5 min each with $\mathrm{mqH}_{2} \mathrm{O}$. Specimens were dehydrated with 5 -min washes of

$43250 \%, 70 \%$ and $95 \%$ ethanol, followed by three 10 -min washes with $100 \%$

433 ethanol, then two quick rinses with propylene oxide (PO). Specimens were

434 embedded in Embed 812 resin (EMS) formulated to medium hardness by rinsing

43530 min each in 1:1 PO to Embed 812, 1:2 PO to Embed 812, then 60 min in 1:4

$436 \mathrm{PO}$ to Embed 812. Specimens were then transferred to $100 \%$ Embed 812 and

437 incubated overnight at room temperature, followed by two subsequent changes

438 of Embed 812, over a total embedding time of $48 \mathrm{hr}$. Samples were then

439 positioned in molds and placed at $60^{\circ} \mathrm{C}$ for $3 \mathrm{~d}$ to polymerize.

440 Sectioning was performed on a Leica UCT ultramicrotome, using glass knives for

441 trimming blocks and generating semi-thin $(1 \mu \mathrm{m})$ sections, and a DiATOME

442 diamond knife for generating thin sections of approximately 60-100 nm thickness

443 (target thickness: $80 \mathrm{~nm}$ ). Sections were flattened with chloroform vapor,

444 transferred onto precoated Formvar/carbon 200 mesh copper grids (\#01803F,

445 Ted Pella, Redding, Calif.), and dried on filter paper. 
446 Grids were imaged with an FEl Tecnai G2 series F20 transmission electron

447 microscope (Hillsboro, Ore.) at $80 \mathrm{kV}$ using a Gatan CCD camera and Gatan

448 Digital Micrograph Software (Pleasanton, Calif.).

\section{Data Availability}

450 All data are available as Supplemental Data Files 1 and 2.

452 Acknowledgements: Sequences were provided by Chris Amemiya, John Burns,

453 Paul Hime, Ryan Kerney, Justin Kratovil, Rachel Mueller, Igor Schneider, Randal

454 Voss, David Weisrock, and Ryan Woodcock (Table S2). Carolyn Marks offered

455 help and guidance with TEM. Carolyn Eng assisted with field collection. This

456 work was performed in part at the Harvard University Center for Nanoscale

457 Systems (CNS), a member of the National Nanotechnology Coordinated

458 Infrastructure Network (NNCI), supported under NSF ECCS award no. 1541959.

459 Z.R.L. was supported by the NSF Graduate Research Fellowship Program.

461 Author contributions: Z.R.L. cloned SFTPC and SFTPC-like from $A$.

462 mexicanum and $P$. cinereus, generated and analyzed transcriptomes, performed

463 phylogenetic and structural analyses, performed TEM, collected and raised

464 animals, generated gene expression data and participated in writing the

465 manuscript. J.A.D. cloned SFTPC-like from D. fuscus and assisted with

466 characterizing the expression of SFTPC-like. J.H. participated in the data

467 analyses and writing of the manuscript. 
469 Competing interests: The authors declare that they have no competing financial

470 interests.

471

\section{References:}

473 1. Whitford WG, Hutchison VH. 1965 Gas exchange in salamanders. Physiol.

$474 \quad$ Zool. 38, 228-242.

475 2. Gatz RN, Crawford EC, Piiper J. 1974 Respiratory properties of the blood

476 of a lungless and gill-less salamander, Desmognathus fuscus. Respir.

$477 \quad$ Physiol. 20, 33-41.

478 3. Feder ME, Burggren WW. 1985 Cutaneous gas exchange in vertebrates:

479 design, patterns, control and implications. Biol. Rev. Camb. Philos. Soc.

$480 \quad 60,1-45$.

481 4. Bickford D, Iskandar D, Barlian A. 2008 A lungless frog discovered on $482 \quad$ Borneo. Curr. Biol. 18, 374-375.

483 5. Wilder IW, Dunn E. 1920 The correlation of lunglessness in salamanders 484 with a mountain brook habitat. Copeia 1920, 63-68.

485 6. Reagan NL, Verrell PA. 1991 The evolution of plethodontid salamanders:

486 did terrestrial mating facilitate lunglessness? Am. Nat. 138, 1307-1313.

487 7. Czopek J. 1965 Quantitative studies on the morphology of respiratory 488 surfaces in amphibians. Acta Anat. (Basel). 62, 296-323.

489 8. Seelye A. 1906 Circulatory and respiratory systems of Desmognathus 490 fusca. Proc. Bost. Soc. Nat. Hist. 32, 335-357.

491 9. Barrows Al. 1900 Respiration of Desmognathus. Anat. Anz. 18, 461-464. 
492 10. Sheafor EA, Wood SC, Tattersall GJ. 2000 The effect of graded hypoxia on 493 the metabolic rate and buccal activity of a lungless salamander

494 (Desmognathus fuscus). J. Exp. Biol. 203, 3785-3793.

495 11. Lombard RE, Wake DB. 1986 Tongue evolution in the lungless salamanders, family Plethodontidae IV. Phylogeny of plethodontid salamanders and the evolution of feeding dynamics. Syst. Zool. 35, 532-

499 12. Wake DB. 1982 Functional and developmental constraints and $500 \quad$ opportunities in the evolution of feeding systems in urodeles. In 501 Environmental Adaptation and Evolution (eds D Mossakowski, G Roth), pp.

502 51-66. Stuttgart: Gustav Fisher.

503 13. Daniels CB, Orgeig S, Smits AW. 1995 The evolution of the vertebrate 504 pulmonary surfactant system. Physiol. Zool. 68, 539-566.

505 14. Whitsett JA, Weaver TE. 2002 Hydrophobic surfactant proteins in lung 506 function and disease. N. Engl. J. Med. 347, 2141-2148.

507 15. Olmeda B, Villén L, Cruz A, Orellana G, Perez-Gil J. 2010 Pulmonary 508 surfactant layers accelerate $\mathrm{O} 2$ diffusion through the air-water interface. 509 Biochim. Biophys. Acta-Biomembr. 1798, 1281-1284.

510 16. Johansson J, Szyperski T, Curstedt T, Wüthrich K. 1994 The NMR 511 structure of the pulmonary surfactant-associated polypeptide SP-C in an 512 apolar solvent contains a valyl-rich alpha-helix. Biochemistry 33, 6015$513 \quad 6023$.

514 17. Hafner D, Germann PG, Hauschke D, Kilian U. 1999 Effects of early 
515 treatment with rSP-C surfactant on oxygenation and histology in rats with 516 acute lung injury. Pulm. Pharmacol. Ther. 12, 193-201.

517 18. Rice WR, Sarin VK, Fox JL, Baatz J, Wert S, Whitsett JA. 1989 Surfactant

518 peptides stimulate uptake of phosphatidylcholine by isolated cells. Biochim.

519 Biophys. Acta 1006, 237-245.

520 19. Weaver TE, Whitsett JA. 1991 Function and regulation of expression of

521 pulmonary surfactant-associated proteins. Biochem. J. 273, 249-264.

522 20. Guyton AC, Moffatt DS, Adiar TH. 1984 Role of alveolar surface tension in 523 transepithelial movement of fluid. In Pulmonary Surfactant (eds B

524 Robertson, L Van Golde, J Batenburg), pp. 171-185. Amsterdam: Elsevier $525 \quad$ Science Publishers.

526 21. Ultsch GR, Gros G. 1979 Mucus as a diffusion barrier to oxygen: Possible 527 role in $\mathrm{O} 2$ uptake at low pH in carp (Cyprinus carpio) gills. Comp. Biochem.

$528 \quad$ Physiol. Part A Physiol. 62, 685-689.

529 22. Sosnowski T, Gradon L, Skoczek M, Drozdiel H. 1998 Experimental 530 evaluation of importance of the pulmonary surfactant for oxygen transfer 531 rate in human lungs. Int. J. Occup. Saf. Ergon. 4, 391-409.

532 23. Bourbon JR, Chailley-Heu B. 2001 Surfactant proteins in the digestive 533 tract, mesentery, and other organs: evolutionary significance. Comp.

534 Biochem. Physiol. A, Mol. Integr. Physiol. 129, 151-161.

535 24. Fisher JH, Shannon JM, Hofmann T, Mason RJ. 1989 Nucleotide and 536 deduced amino acid sequence of the hydrophobic surfactant protein SP-C 537 from rat: expression in alveolar type II cells and homology with SP-C from 
538 other species. Biochim. Biophys. Acta 995, 225-30.

539 25. Wert SE, Glasser SW, Korfhagen TR, Whitsett JA. 1993 Transcriptional

540 elements from the human SP-C gene direct expression in the primordial

541 respiratory epithelium of transgenic mice. Dev. Biol. 156, 426-443.

542 26. Wilder IW. 1925 The Morphology of Amphibian Metamorphosis.

$543 \quad$ Northampton: Smith College.

544 27. Lewis ZR. 2016 Causes and Consequences of Lung Loss in Salamanders.

545 PhD Dissertation. Harvard University.

546 28. Schmitz G, Müller G. 1991 Structure and function of lamellar bodies, lipid-

547 protein complexes involved in storage and secretion of cellular lipids. J.

$548 \quad$ Lipid Res. 32, 1539-1570.

549 29. Matoltsy AG, Bednarz JA. 1975 Lamellar bodies of the turtle epidermis. J.

$550 \quad$ Ultrastructure Res. 53, 128-132.

551 30. Grayson S, Johnson-Winegar AG, Wintroub BU, Isseroff RR, Epstein EH,

552 Elias PM. 1985 Lamellar body-enriched fractions from neonatal mice:

553 preparative techniques and partial characterization. J. Invest. Dermatol. 85,

554 289-294.

555 31. Bryant DM et al. 2017 A tissue-mapped axolotl de novo transcriptome 556 enables identification of limb regeneration factors. Cell Rep. 18, 762-776.

557 32. Daniels CB, Orgeig S, Wilsen J, Nicholas TE. 1994 Pulmonary-type

558 surfactants in the lungs of terrestrial and aquatic amphibians. Respir.

$559 \quad$ Physiol. 95, 249-258.

560 33. Cass AN, Servetnick MD, McCune AR. 2013 Expression of a lung 
561 developmental cassette in the adult and developing zebrafish swimbladder.

$562 \quad$ Evol. Dev. 132, 119-132.

563 34. Conant GC, Wolfe KH. 2008 Turning a hobby into a job: How duplicated 564 genes find new functions. Nat. Rev. Genet. 9, 938-950.

565 35. Lan X, Pritchard JK. 2016 Coregulation of tandem duplicate genes slows 566 evolution of subfunctionalization in mammals. Science 352, 1009-13.

567 36. Nehrt NL, Clark WT, Radivojac P, Hahn MW. 2011 Testing the ortholog 568 conjecture with comparative functional genomic data from mammals. PLoS 569 Comput. Biol. 7, e1002073.

$57037 . \quad H u n t e r$ JP. 1998 Key innovations and the ecology of macroevolution.

571 Trends Ecol. Evol. 13, 31-36.

572 38. Lewis ZR, Hanken J. 2017 Convergent evolutionary reduction of atrial 573 septation in lungless salamanders. J. Anat. 230, 16-29.

574 39. Bordzilovskaya N, Dettlaff T, Duhon S, Malacinski G. 1989 Developmental575 stage series of axolotl embryos. In Developmental Biology of the Axolotl 576 (eds J Armstrong, G Malacinski), pp. 201-219. Oxford: Oxford University 577 Press.

578 40. Nye HLD, Cameron JA, Chernoff EAG, Stocum DL. 2003 Extending the 579 table of stages of normal development of the axolotl: limb development. 580 Dev. Dyn. 226, 555-60.

581 41. Kerney R. 2011 Embryonic staging table for a direct-developing 582 salamander, Plethodon cinereus (Plethodontidae). Anat. Rec. 294, 1796$583 \quad 808$. 
584 42. Bolger AM, Lohse M, Usadel B. 2014 Trimmomatic: a flexible trimmer for $585 \quad$ Illumina sequence data. Bioinformatics 30, 2114-2120.

586 43. Langmead B, Trapnell C, Pop M, Salzberg SL. 2009 Ultrafast and memory587 efficient alignment of short DNA sequences to the human genome.

$588 \quad$ Genome Biol. 10, R25.

589 44. Grabherr MG et al. 2011 Full-length transcriptome assembly from RNA590 Seq data without a reference genome. Nat. Biotechnol. 29, 644-652.

591 45. Haas BJ et al. 2013 De novo transcript sequence reconstruction from RNA592 seq using the Trinity platform for reference generation and analysis. Nat.

$593 \quad$ Protoc. 8, 1494-512.

594 46. Hughes AL. 2007 Evolution of the lung surfactant proteins in birds and 595 mammals. Immunogenetics 59, 565-72.

596 47. Hedlund J, Johansson J, Persson B. 2009 BRICHOS - a superfamily of 597 multidomain proteins with diverse functions. BMC Res. Notes 2, 180.

598 48. Löytynoja A, Goldman N. 2010 webPRANK: a phylogeny-aware multiple 599 sequence aligner with interactive alignment browser. BMC Bioinformatics $600 \quad 11,579$.

601 49. Abascal F, Zardoya R, Posada D. 2005 ProtTest: selection of best-fit 602 models of protein evolution. Bioinformatics 21, 2104-2105.

603 50. Jones DT, Taylor WR, Thornton JM. 1992 The rapid generation of mutation 604 data matrices from protein sequences. Bioinformatics 8, 275-282.

605 51. Ronquist F et al. 2012 MrBayes 3.2: Efficient Bayesian phylogenetic 606 inference and model choice across a large model space. Syst. Biol. 61, 
$607 \quad 539-542$.

608 52. Stamatakis A. 2006 RAxML-VI-HPC: maximum likelihood-based

609 phylogenetic analyses with thousands of taxa and mixed models.

$610 \quad$ Bioinformatics 22, 2688-90.

611 53. Waterhouse AM, Procter JB, Martin DMA, Clamp M, Barton GJ. 2009

612 Jalview Version 2-a multiple sequence alignment editor and analysis

$613 \quad$ workbench. Bioinformatics 25, 1189-1191.

614 54. Boussau B, Szollosi GJ, Duret L, Gouy M, Tannier E, Daubin V. 2013

615 Genome-scale coestimation of species and gene trees. Genome Res. 23,

$616 \quad 323-330$.

617 55. Pyron RA, Wiens JJ. 2011 A large-scale phylogeny of Amphibia including 618 over 2,800 species, and a revised classification of extant frogs, 619 salamanders, and caecilians. Mol. Phylogenet. Evol. 61, 543-583.

620 56. Xu D, Zhang Y. $2012 \mathrm{Ab}$ initio protein structure assembly using continuous 621 structure fragments and optimized knowledge-based force field. Proteins $62280,1715-1735$.

623 57. Yang J, Yan R, Roy A, Xu D, Poisson J, Zhang Y. 2015 The I-TASSER 624 Suite: protein structure and function prediction. Nat. Methods 12, 7-8.

625 58. Arnold K, Bordoli L, Kopp J, Schwede T. 2006 The SWISS-MODEL 626 workspace: a web-based environment for protein structure homology 627 modelling. Bioinformatics 22, 195-201. 


\section{Figures:}
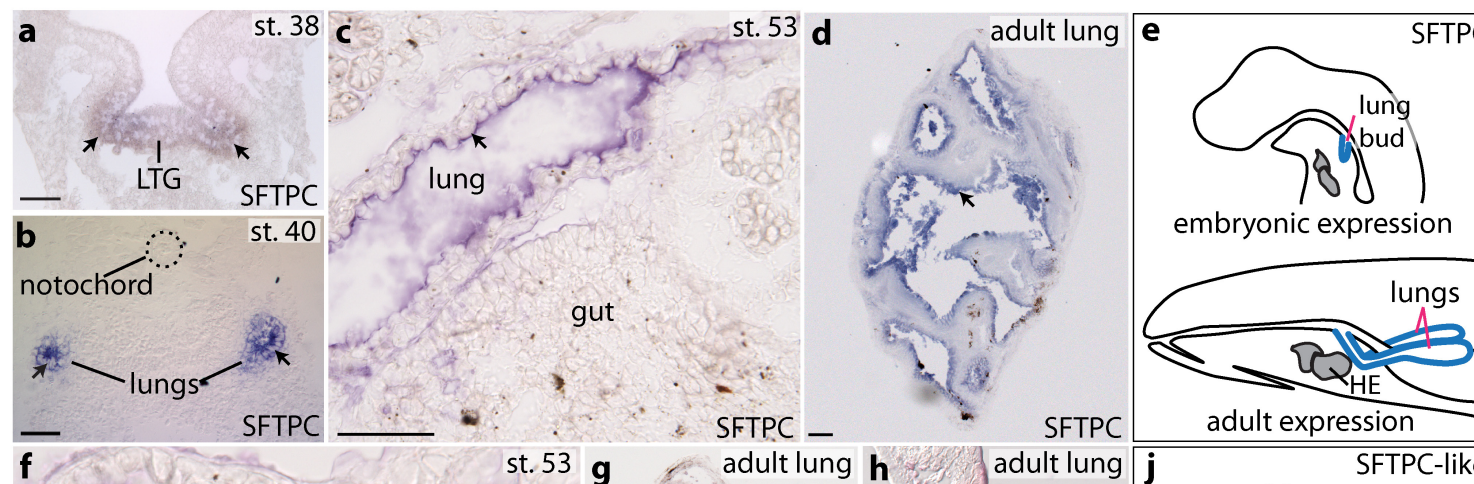

embryonic expression

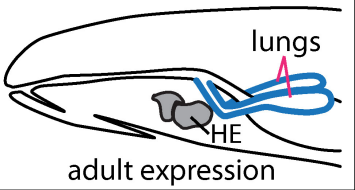

\section{f}

st. $53 \mathbf{g}$ adult lung $\mathbf{h}$

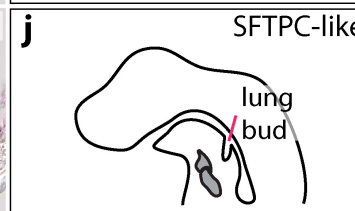

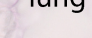
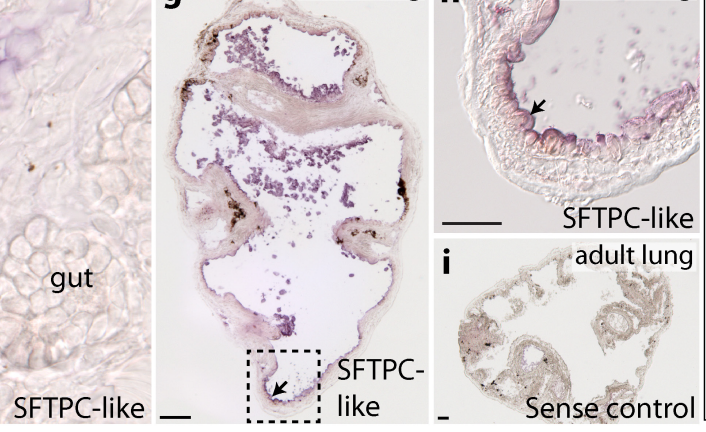

embryonic expression

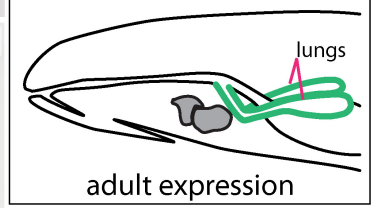

631 Figure 1. Expression patterns of Surfactant-Associated Protein C (SFTPC)

632 and SFTPC-like in a lunged salamander, Ambystoma mexicanum,

633 visualized with antisense wholemount in-situ hybridization. Arrows point to

634 representative regions of expression. SFTPC is expressed in the embryonic

635 laryngotracheal groove (LTG) a, or lungs $\mathbf{b}-\mathbf{d}$, of all stages examined between

636 embryo (st. 40), juvenile (st. 53) and adult. f-h, SFTPC-like is also expressed

637 specifically in the lung in juveniles and adults, but at a lower level than SFTPC; it

638 is not expressed in embryos. $\mathbf{h}$, Boxed region in $\mathbf{g}$. $\mathbf{i}$, Negative (sense) control run

639 in parallel with SFTPC-like. e, j, Schematic sagittal views summarize the

640 expression sites of SFTPC and SFTPC-like. Blue regions denote high

641 expression; green indicates lower level. a, b, $\mathbf{d}$ and $\mathbf{g}-\mathbf{i}$ depict transverse

642 sections; $\mathbf{c}$ and $\mathbf{f}$ are sagittal sections, anterior to the left. Scale bars: $100 \mu \mathrm{m}$.

643 Additional abbreviation: HE, heart. 

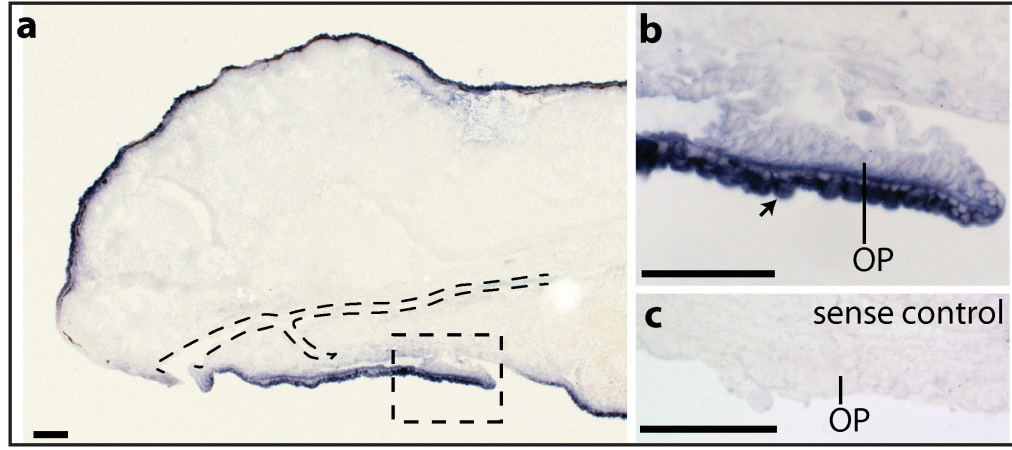

d

D. fuscus, st. 20, embryo
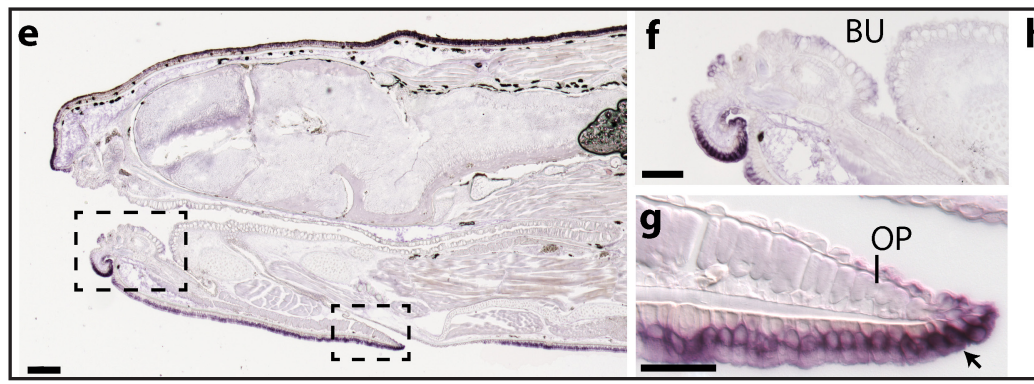

h D. fuscus, $25 \mathrm{~mm}$, larva

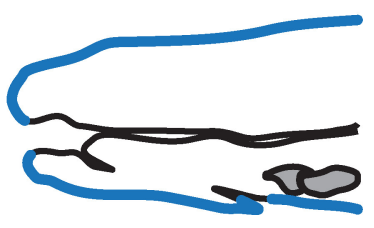

SFTPC-like

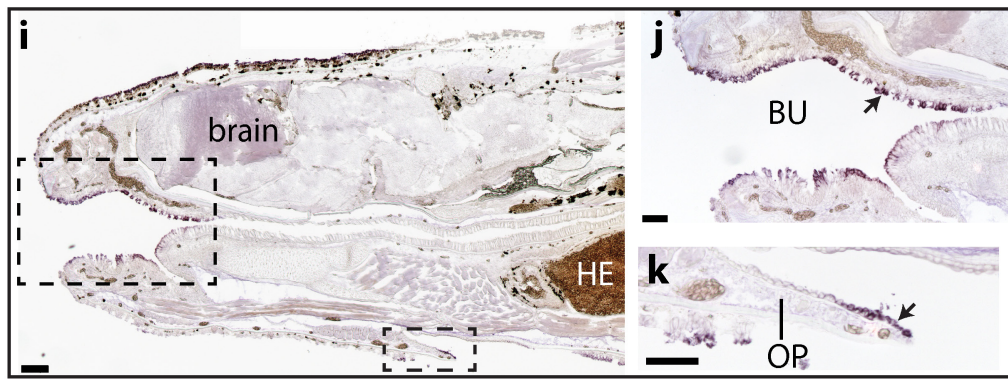

I
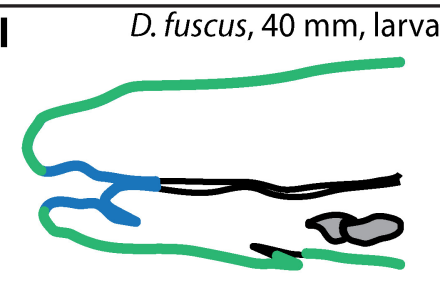

SFTPC-like
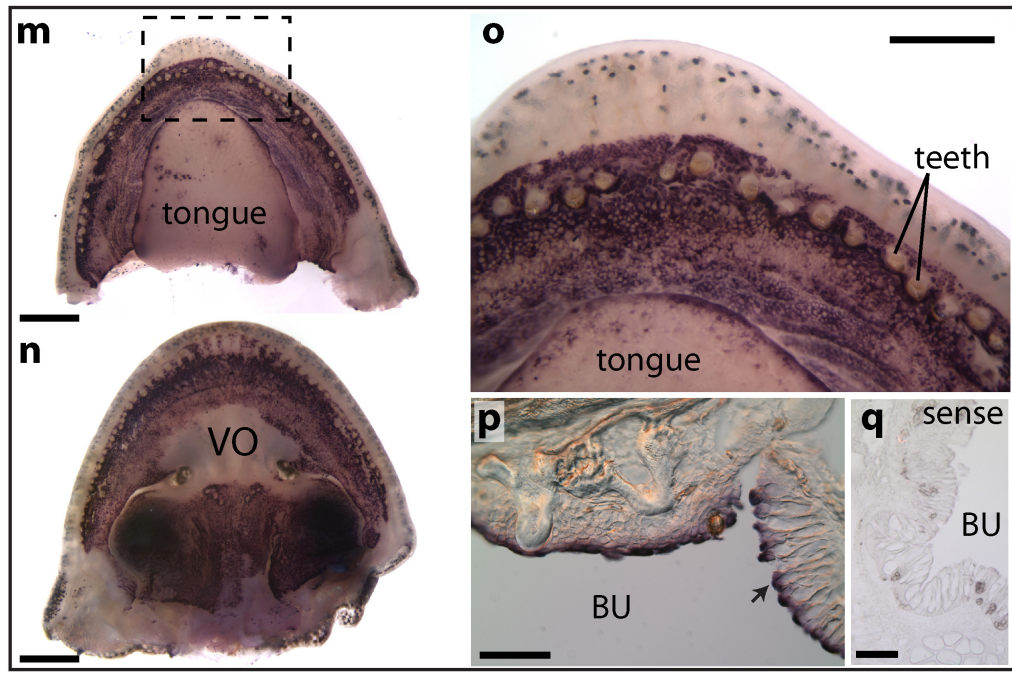

$\mathbf{r}$

D. fuscus, adult

644

645 Figure 2. Expression of Surfactant-Associated Protein C-like (SFTPC-like)

646 in the lungless salamander Desmognathus fuscus, visualized with

647 antisense wholemount in-situ hybridization. Arrows point to representative 
648 regions of expression. a-c, In embryos, SFTPC-like is expressed in the

649 integument. b, Boxed region in a. c, Negative (sense) control. e-g, SFTPC-like is

650 expressed in the larval integument, $25 \mathrm{~mm}$ total length. i-k, SFTPC-like in a larva

651 just prior to metamorphosis, $40 \mathrm{~mm}$ total length. Expression has declined in the

652 integument but is now present in the buccopharyngeal mucosa (BU). $\mathbf{m}-\mathbf{q}$, Adult

653 expression of SFTPC-like is confined to the buccopharyngeal cavity. $\mathbf{d}, \mathbf{h}, \mathbf{I}, \mathbf{r}$,

654 Schematic sagittal views summarize the expression sites of SFTPC-like. Blue

655 regions correspond to high expression; green indicates lower level. a-I are

656 sagittal sections, anterior to the left; $\mathbf{p}$ and $\mathbf{q}$ are transverse sections. Scale bars:

657 a-c, e, f, i-k, p, q, $100 \mu \mathrm{m} ; \mathbf{g}, 50 \mu \mathrm{m} ; \mathbf{m}, \mathbf{n}, 1 \mathrm{~mm} ; \mathbf{0}, 0.5 \mathrm{~mm}$. Additional

658 abbreviations: HE, heart; OP, opercular covering; VO, vomer. 

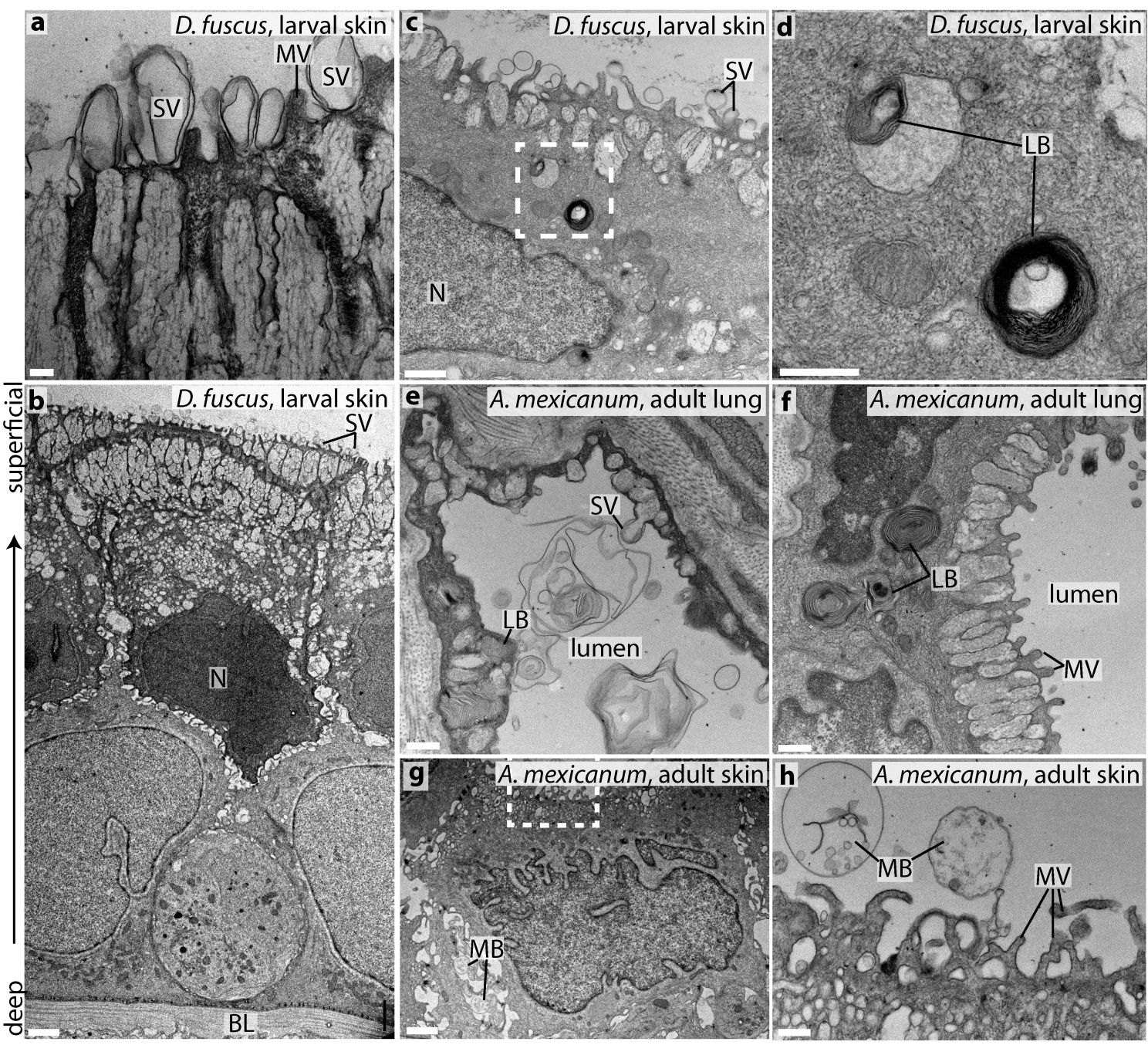

Figure 3. Secretory activity and lamellar bodies in the larval integument of

661 lungless Desmognathus fuscus resemble those in the lung of Ambystoma

662 mexicanum. a-d, Transmission electron micrographs of a 24-mm D. fuscus. a,

663 The superficial (apical) surface is covered with secretory vesicles (SV), which

664 emerge from columnar vacuolar structures, and is interspersed with microvilli

665 (MV). b, Sagittal section through the epidermis; the superficial surface points

666 upwards. c,d, Lamellar bodies (LB), indicative of surfactant production, are

667 visible in the integument. The boxed region in $\mathbf{c}$ is enlarged in $\mathbf{d}$. e,f, Lamellar

668 bodies and secretory vesicles in the distal portion of the lung of an adult $A$. 
669 mexicanum; transverse section. g,h, Transverse section of gular integument of

670 adult $A$. mexicanum. The boxed region in $\mathbf{g}$ is enlarged in $\mathbf{h}$. Multivesicular

671 bodies (MB) are visible in extracellular spaces in $\mathbf{g}$ and external to the skin in $\mathbf{h}$,

672 but there is no indication of active secretion of vesicles. The integument does not

673 play a pronounced secretory role in this species. Additional abbreviations: BL,

674 basal lamina; N, nucleus. Scale bars: a, $200 \mathrm{~nm} ; \mathbf{b}, \mathbf{g}, 2 \mu \mathrm{m} ; \mathbf{c}, 1 \mu \mathrm{m} ; \mathbf{d}, \mathbf{e}, \mathbf{f}, \mathbf{h}$,

$675500 \mathrm{~nm}$. 


\section{Supporting Information}

\section{Supplemental Text}

\section{SFTPC expression specificity}

The expression pattern of SFTPC is highly conserved: all tetrapods express SFTPC exclusively in the lungs [1-9]. In anamniotes, SFTPC is expressed throughout the lung $[5,6,10]$, whereas in mammals it is confined to alveolar type II cells. Four reports cite expression of SFTPC outside of the lungs in humans, but each report has methodological problems, including possible contamination, that may make such claims unreliable. Mo et al. (2006) report SFTPC in human fetal and adult skin [11]. This claim, however, relies on immunohistochemical data obtained with an antibody that may yield spurious labeling, and on RT-PCR data that was not followed up with sequencing. RT-PCR is subject to contamination and mispriming. Bräuer et al. (2009) report SFTPC expression in submandibular and parotid glands based on RT-PCR and western immunoblots [12]. The western blots reveal a protein of the expected size of the SFTPC pro-protein, and RT-PCR of focal cDNA is performed alongside a positive control, but there is no follow-up sequencing. Schicht et al. (2015) report SFTPC in saliva from human patients based on western blots and ELISA [13]. The antibody used to detect SFTPC is not identified, however, and the isolated band is at $16 \mathrm{kDa}$ while SFTPC proprotein is $21 \mathrm{kDa}$ and mature SFTPC $3.7 \mathrm{kDa}$ [14]. Additionally, saliva may be subject to contamination by surfactant produced in the lungs. Finally, Schob et al. (2013) report SFTPC expression in central nervous system tissue and cerebrospinal fluid based on RT-PCR, but they fail to rule out the possibility of genomic DNA contamination [15]. Their western blots also fail to demonstrate a band at the expected size for SFTPC given the antibody they employed, and the authors express confusion about how mRNA for SFTPC could be present in cerebrospinal fluid. In sum, there are problems with all recent studies that cite extrapulmonary expression of SFTPC in humans. At the same time, numerous studies in mammals and frogs, including ISH and reporter knockins, have failed to demonstrate extrapulmonary expression of SFTPC. For instance, a mouse line with Cre recombinase knocked in to the SFTPC locus fails to label cells outside of the lung when crossed to a reporter line [16]. Nevertheless, it remains possible that humans and perhaps other animals endogenously express SFTPC outside of the lungs. Optimally, in situ hybridization and transcriptome sequencing should be used to validate the human results presented above. 


\section{Evidence for Duplication of SFTPC}

42 Both SFTPC and SFTPC-like diverge within exonic regions, but not according to

43 putative splice boundaries (Fig. S1a), which indicates that SFTPC-like is not an

44 isoform of SFTPC. While SFTPC-like is divergent from SFTPC sequences, it is

45 not an ortholog of a closely related BRICHOS domain-containing gene (Fig.

46 S1b). We found SFTPC-like expressed in ten species of lunged and lungless

47 salamanders (Fig. S1a, b; Supplemental Data File 1), most of which also express

48 SFTPC. SFTPC-like is not found in genomes or transcriptomes of any other

49 tetrapods, or even other vertebrates.

51 The most parsimonious explanation for the corresponding gene tree is that the

52 tetrapod ortholog of SFTPC was duplicated in the salamander lineage following

53 its divergence from frogs, followed by substantial sequence divergence between

54 SFTPC and SFTPC-like (Fig. S1b). Low statistical support at the SFTPC-like

55 node should be interpreted as a polytomy, and long-branch attraction likely has

56 caused an artifactual affiliation between coelacanth and lungfish SFTPC

57 orthologs and salamander SFTPC-like. We applied PHYLDOG [17] to explicitly

58 test for gene duplications of SFTPC. Given a guide tree with known phylogenetic

59 relationships (Fig. S2), PHYLDOG predicts that SFTPC-like arose by gene

60 duplication (Fig. S3). SFTPC-like has been meiotically mapped to linkage group

616 in Ambystoma mexicanum, a lunged salamander, and is located within a region

62 syntenic to human chromosome 15 [18]. SFTPC-like and SFTPC have been

63 assembled to two separate genomic scaffolds from $A$. mexicanum [19],

64 supporting SFTPC-like's origin via gene duplication. 


\section{Supporting Information Tables:}

66

67 Table S1. Primers used to clone SFTPC and SFTPC-like from Ambystoma

68

69

70

71

\begin{tabular}{llll}
\hline Gene & Species & Forward & Reverse \\
\hline SFTPC & A. mexicanum & 5'-CAC ACA GAR AMG ATT TTC CAG ATG-3' & 5'-CGT CTT GTC CAT TTT TGT KAB GTA GCA-3' \\
SFTPC-like & A. mexicanum & 5'-AAG ATG GAA ACC GGC AGC AAG C-3' & 5'-CGT CTT GTC CAT TTT TGT KAB GTA GCA-3' \\
SFTPC-like & D. fuscus & 5'-AAG ATG GAA ACC GGC AGC AAG C-3' & 5'-AGT ATT GGA AGC GGT CTG GGT G-3' \\
SFTPC-like & P. cinereus & 5'-AAG ATG GAA ACC GGC AGC AAG C-3' & 5'-GGT GTA GTC ATA GAC CAC-3' $^{2}$
\end{tabular}




\section{Supporting Information Figures:}

a
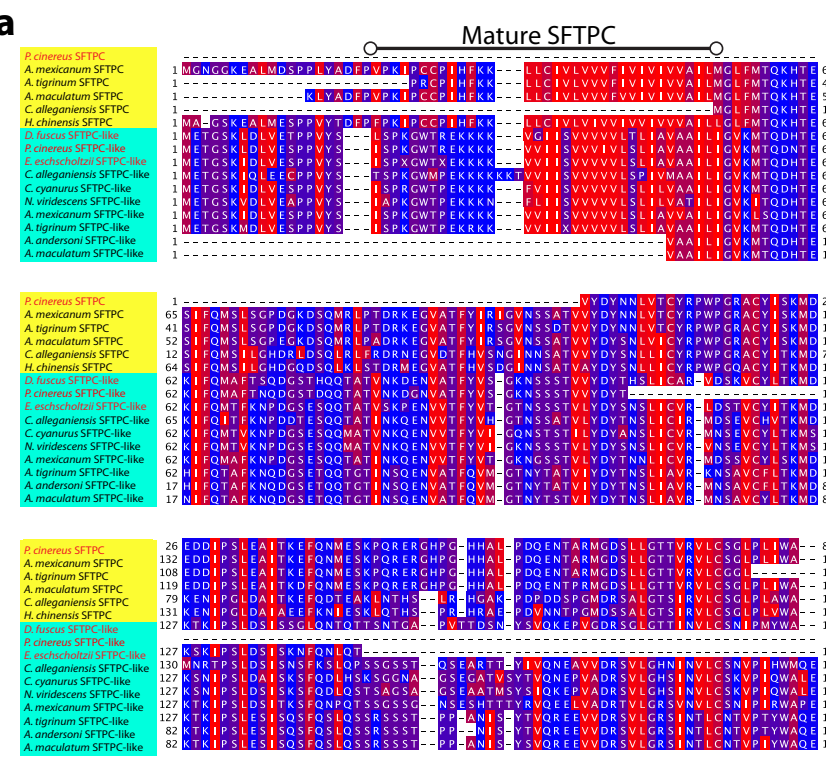

C

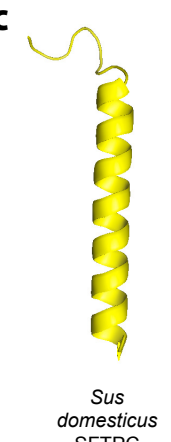

SFTPC
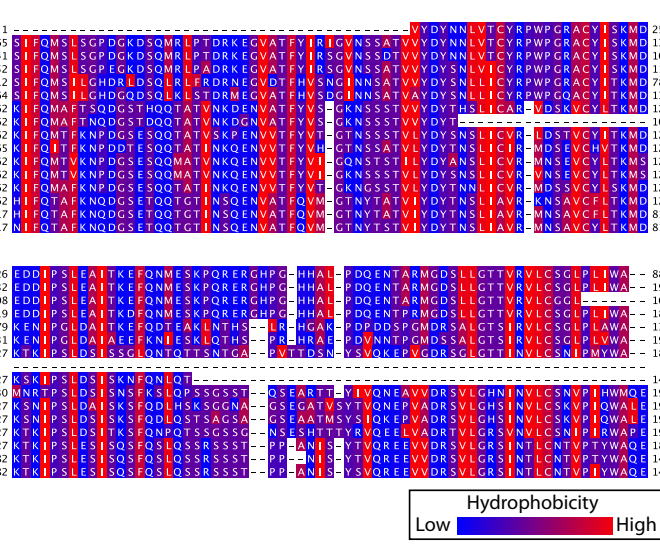

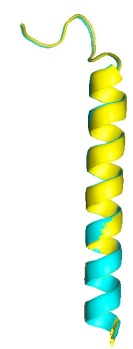

D. fuscus

SWISS-MODEL
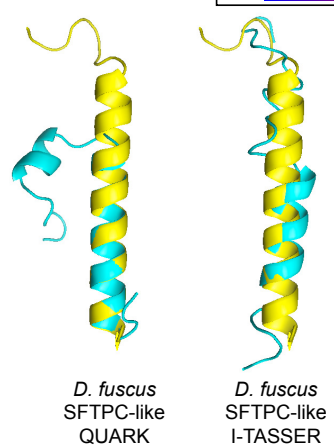

b

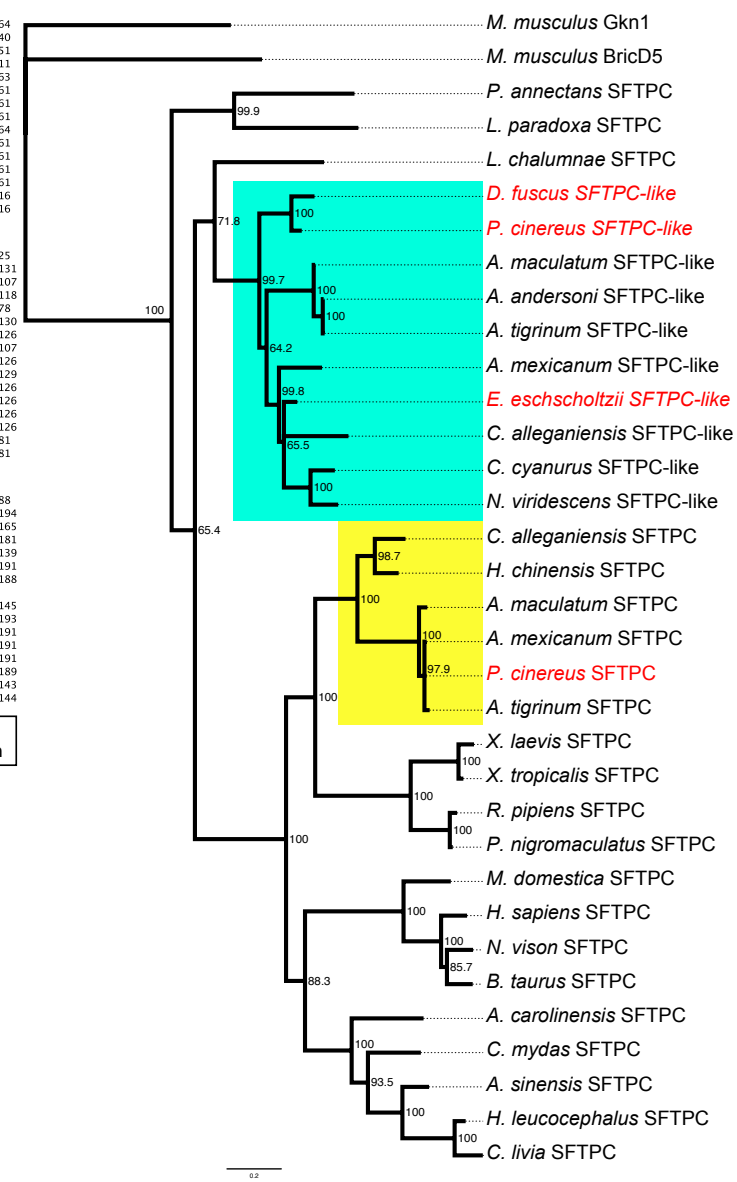

\section{Figure S1. A novel form of Surfactant-Associated Protein C (SFTPC) is} expressed in several species of salamanders. a, Amino acid alignment of SFTPC (yellow) and SFTPC-like (cyan) sequences reveals conservation of hydrophobic residues within the mature peptide domain. Full species names and accession numbers are listed in Supplemental Data File 1. Lungless (plethodontid) species are in red font. b, Bayesian $95 \%$ maximum clade credibility tree for SFTPC reveals SFTPC-like transcripts in 10 species of salamanders. SFTPC-like is not a related ortholog because it is nested within the SFTPC phylogeny. SFTPC-like is not found in any genome or transcriptome outside of salamanders. Node values are posterior probabilities; scale bar is expected changes per site. c, Predicted secondary structure of SFTPC-like from Desmognathus fuscus. SFTPC-like structure predictions (cyan) utilizing SWISSMODEL [28], QUARK Ab initio predictions [29] and I-TASSER [30] are aligned with the resolved SFTPC mature peptide (yellow) [31]. 


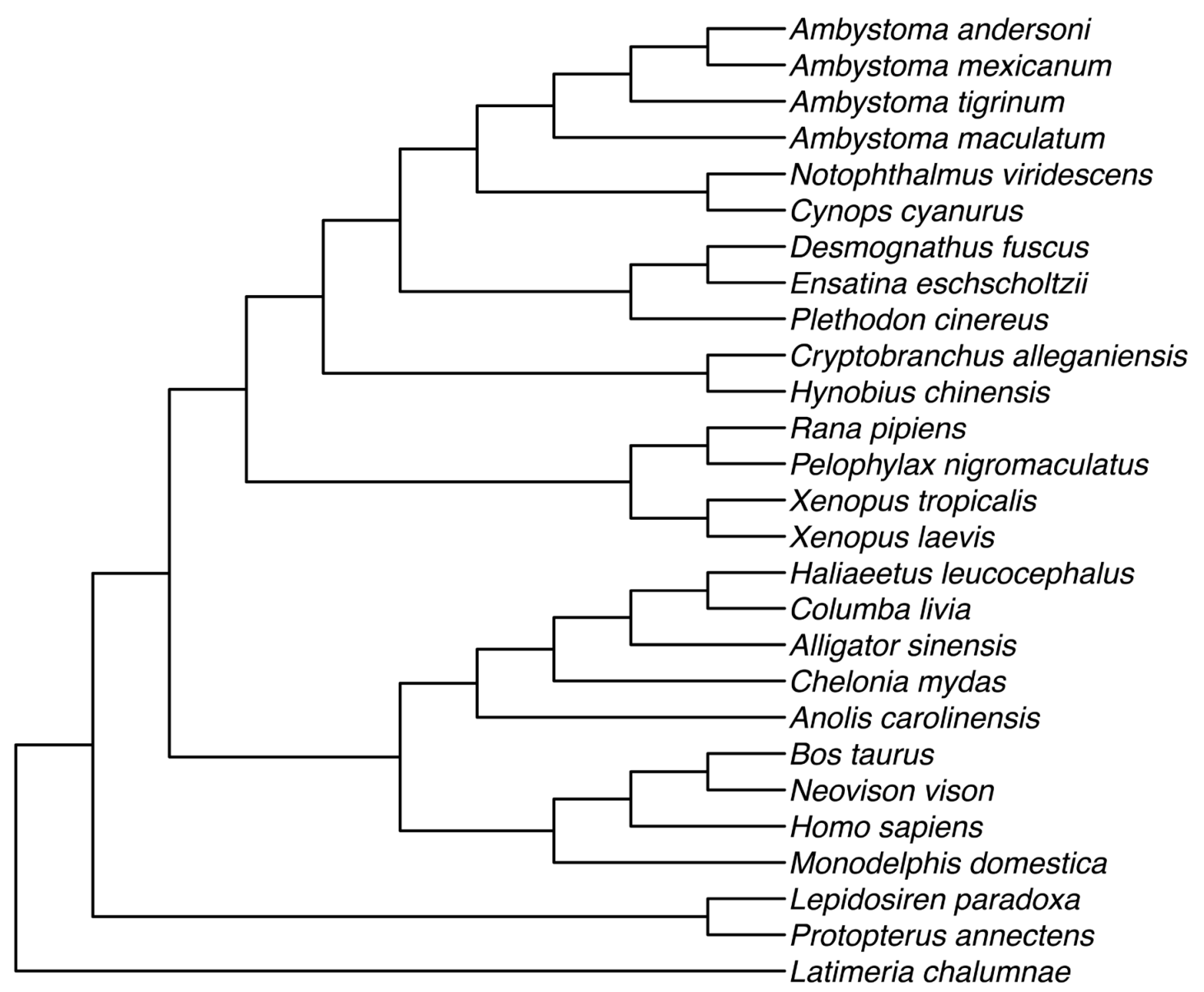

90

91 Figure S2. Guide tree for PHYLDOG. NCBI taxonomy was used to generate the 92 tree, combined with Pyron and Wiens (2011) [32] for amphibian taxonomy. 


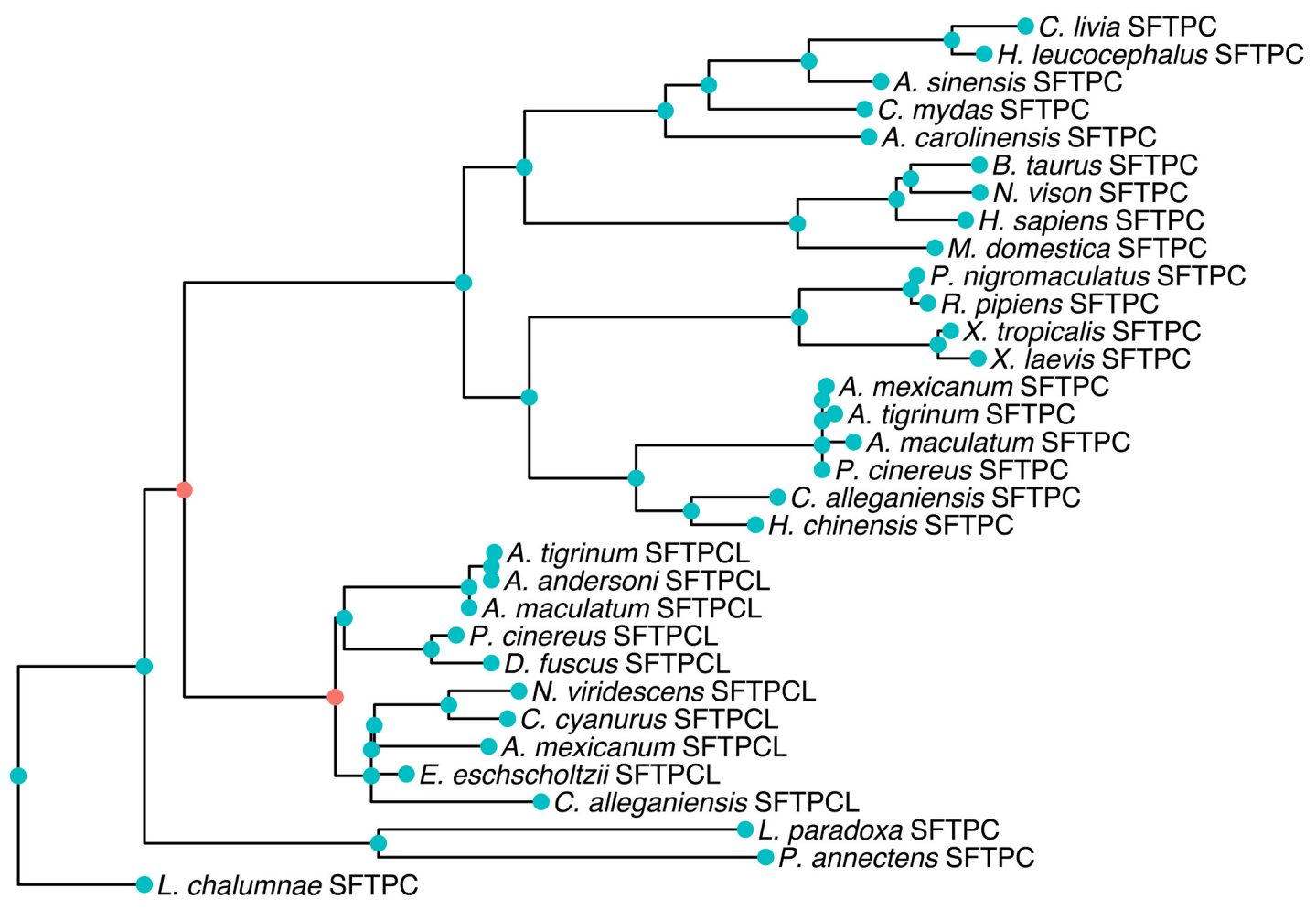

94 Figure S3. Gene duplications predicted by PHYLDOG. The two nodes where

95 a gene duplication event is predicted are colored red. Blue nodes indicate

96 divergence due to speciation events. PHYLDOG predicts that SFTPC-like

97 (SFTPCL) originated due to gene duplication. A second duplication event of

98 SFTPC-like is predicted in salamanders. While most species of salamanders

99 appear to express only one form of SFTPC-like, several species express SFTPC-

100 like transcripts with slight sequence differences, as noted in Supplemental Data

101 File 1. Further work is needed to determine if these sequence differences can be

102 attributed to further duplications of SFTPC-like or are the result of assembly error

103 or alternative splicing. Only one sequence per species was selected for

104 phylogenetic analysis. Complete species names are provided in Figure S2 and

105 Table S2. 

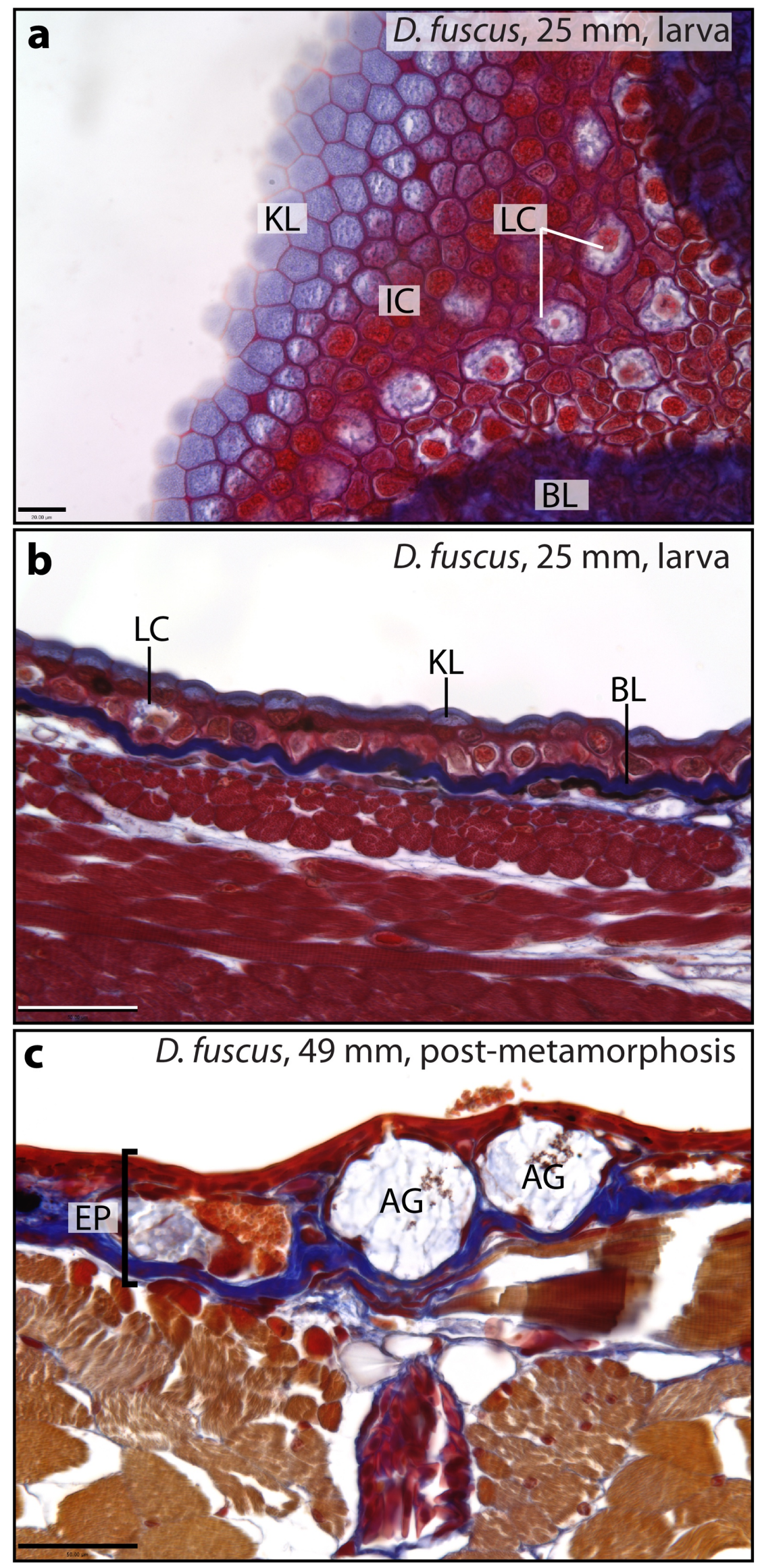
107 Figure S4. Histology of the integument in Desmognathus fuscus before and

108 after metamorphosis. a, Tangential section through the gular region of a larva

109 shows the layers of the integument (from left to right): flattened, cuticle-like

110 keratinized layer (KL); an inner cell layer (IC); large cuboidal Leydig cells (LC)

111 intermingled with capillaries and other supporting cells; basal lamina (BL). b,

112 Sagittal section from the abdominal region of a larva. c, Transverse section from

113 a recently metamorphosed specimen showing the acinous glands (AG) and a

114 greatly thickened epidermis (EP). Mallory's trichrome stain. Scale bars: a, $20 \mu \mathrm{m}$;

115 b,c, $50 \mu \mathrm{m}$.

116 


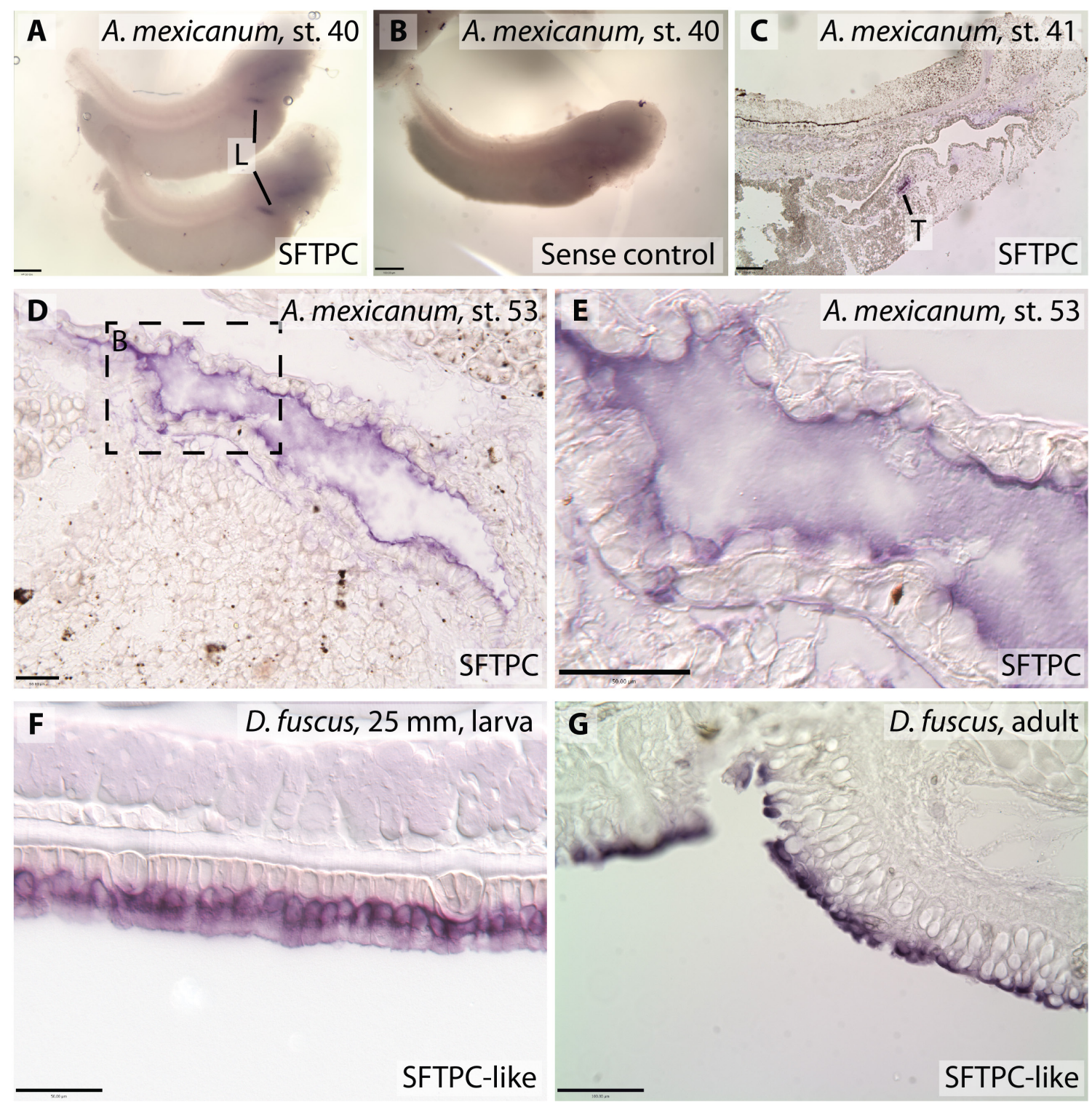

\section{Figure S5. Additional images of SFTPC and SFTPC-like expression} expression specific to the lungs (L). b, SFTPC sense control at the same stage shows no lung expression. c, Midsagittal section of $A$. mexicanum embryo stained for SFTPC shows expression in the trachea $(T)$, but no expression in the integument or buccopharynx. d,e, SFTPC expression in Ambystoma mexicanum lung is confined to the squamous epithelial cells lining the lumen. $\mathbf{e}$ is an enlargement of the boxed region in d. f, SFTPC-like expression in Desmognathus fuscus integument is confined to the apical cellular layer. $\mathbf{g}$, SFTPC-like expression in adult $D$. fuscus buccal epithelium. Scale bars: d,e,f, 50 $\mu \mathrm{m} ; \mathbf{a}, \mathbf{b}, \mathbf{c}, \mathbf{g} 100 \mu \mathrm{m}$. 

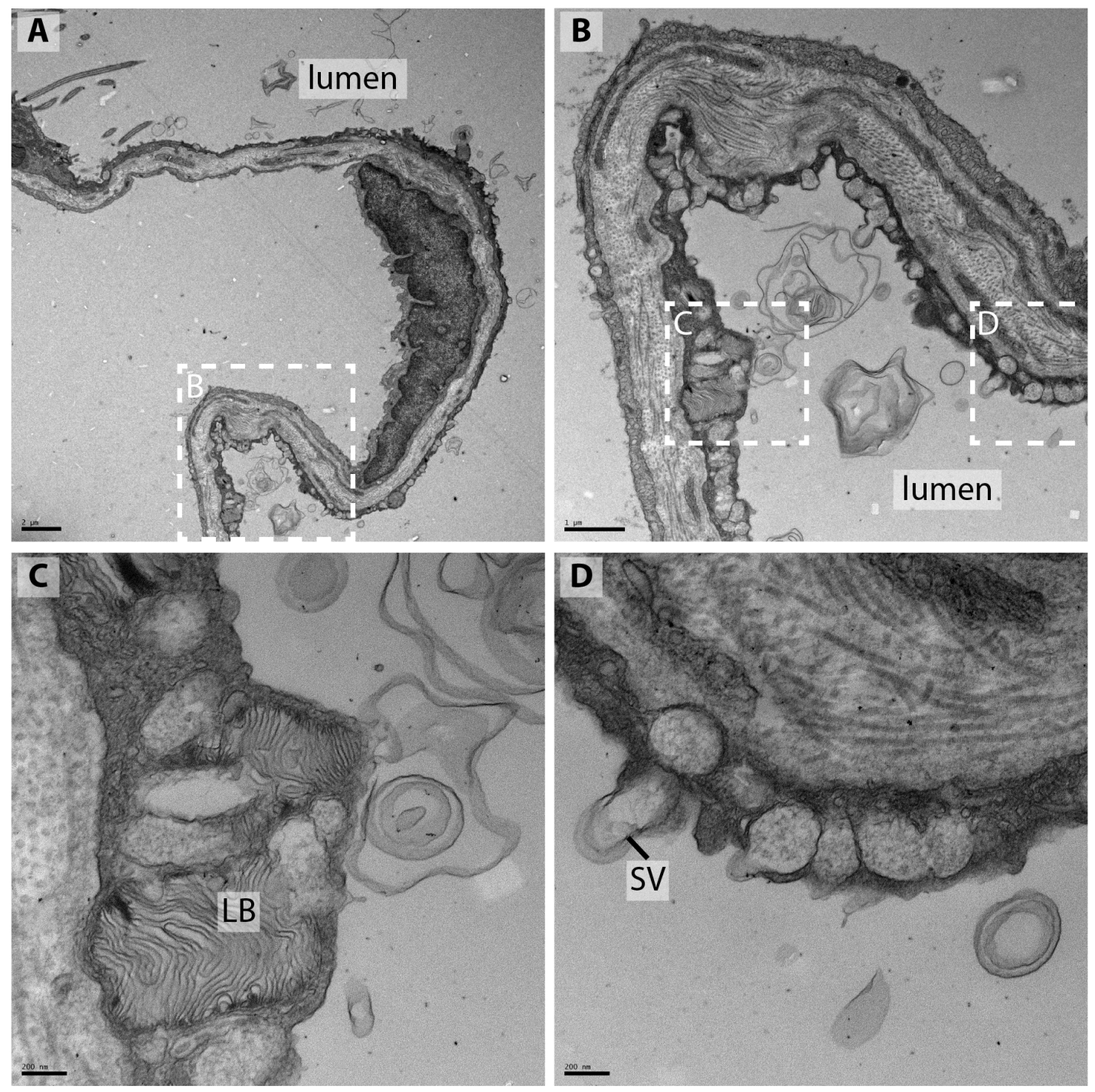

Figure S6. Ultrastructure of alveolar epithelial cells in adult Ambystoma mexicanum. a, low magnification view of the pulmonary epithelium. The lumen of the lung is to the right. $\mathbf{b}$, enlargement of boxed area in $\mathbf{a}$. $\mathbf{c}, \mathbf{d}$, enlargement of boxed regions in $\mathbf{b}$ show lamellar bodies (LB) and secretory vesicles (SV). Scale bars: a, $2 \mu \mathrm{m} ; \mathbf{b}, 1 \mu \mathrm{m} ; \mathbf{c}, \mathbf{d}, 200 \mathrm{~nm}$.

\section{Captions for Supplemental Data Files:}

142 Supplemental Data File 1: Excel spreadsheet with all sequence data used for the 143 study.

144 Supplemental Data File 2: A FASTA amino acid alignment used to generate the 145 gene tree. 


\section{Supporting Information References:}

1. Bourbon JR, Chailley-Heu B. 2001 Surfactant proteins in the digestive tract, mesentery, and other organs: evolutionary significance. Comp. Biochem. Physiol. A, Mol. Integr. Physiol. 129, 151-161.

2. Fisher JH, Shannon JM, Hofmann T, Mason RJ. 1989 Nucleotide and deduced amino acid sequence of the hydrophobic surfactant protein SP-C from rat: expression in alveolar type II cells and homology with SP-C from other species. Biochim. Biophys. Acta 995, 225-30.

3. Glasser SW, Burhans MS, Eszterhas SK, Bruno MD, Korfhagen TR. 2000 Human SP-C gene sequences that confer lung epithelium-specific expression in transgenic mice. Am. J. Physiol. Lung Cell. Mol. Physiol. 278, L933-45.

4. Wert SE, Glasser SW, Korfhagen TR, Whitsett JA. 1993 Transcriptional elements from the human SP-C gene direct expression in the primordial respiratory epithelium of transgenic mice. Dev. Biol. 156, 426-443.

5. Rankin SA et al. 2015 A molecular atlas of Xenopus respiratory system development. Dev. Dyn. 244, 69-85.

6. Hyatt BA, Resnik ER, Johnson NS, Lohr JL, Cornfield DN. 2007 Lung specific developmental expression of the Xenopus laevis surfactant protein $\mathrm{C}$ and $\mathrm{B}$ genes. Gene Expr. Patterns 7, 8-14.

7. Weaver TE, Whitsett JA. 1991 Function and regulation of expression of pulmonary surfactant-associated proteins. Biochem. J. 273, 249-264.

8. Wohlford-Lenane CL, Durham PL, Snyder JM. 1992 Localization of Surfactant-associated Protein C (SP-C) mRNA in fetal rabbit lung tissue by in situ hybridization. Am. J. Respir. Cell Mol. Biol. 6, 225-234.

9. Yin A, Winata CL, Korzh S, Korzh V, Gong Z. 2010 Expression of components of Wnt and Hedgehog pathways in different tissue layers during lung development in Xenopus laevis. Gene Expr. Patterns 10, 33844.

10. Rankin SA, Gallas AL, Neto A, Gómez-Skarmeta JL, Zorn AM. 2012 Suppression of Bmp4 signaling by the zinc-finger repressors Osr1 and Osr2 is required for Wnt/ $\beta$-catenin-mediated lung specification in Xenopus. Development 139, 3010-20.

11. Mo YK, Kankavi O, Masci PP, Mellick GD, Whitehouse MW, Boyle GM, Parsons PG, Roberts MS, Cross SE. 2006 Surfactant protein expression in human skin: evidence and implications. J. Invest. Dermatol. 127, 381-386.

12. Bräuer L, Möschter S, Beileke S, Jäger K, Garreis F, Paulsen FP. 2009 Human parotid and submandibular glands express and secrete surfactant proteins A, B, C and D. Histochem. Cell Biol. 132, 331-8.

13. Schicht $\mathrm{M}$ et al. 2015 The distribution of human surfactant protein within the oral cavity and their role during infectious disease of the gingiva. Ann. Anat. 199, 92-7.

14. Beers MF, Mulugeta S. 2005 Surfactant protein $C$ biosynthesis and its emerging role in conformational lung disease. Annu. Rev. Physiol. 67, 663-696. 
15. Schob S, Schicht M, Sel S, Stiller D, Kekulé A, Paulsen F, Maronde E, Bräuer L. 2013 The detection of surfactant proteins A, B, C and D in the human brain and their regulation in cerebral infarction, autoimmune conditions and infections of the CNS. PLoS One 8, e74412.

16. Barkauskas CE, Cronce MJ, Rackley CR, Bowie EJ, Keene DR, Stripp BR, Randell SH, Noble PW, Hogan BLM. 2013 Type 2 alveolar cells are stem cells in adult lung. J. Clin. Invest. 123, 3025-36.

17. Boussau B, Szollosi GJ, Duret L, Gouy M, Tannier E, Daubin V. 2013 Genome-scale coestimation of species and gene trees. Genome Res. 23, 323-330.

18. Voss SR, Kump DK, Putta S, Pauly N, Reynolds A, Henry RJ, Basa S, Walker JA, Smith JJ. 2011 Origin of amphibian and avian chromosomes by fission, fusion, and retention of ancestral chromosomes. Genome Res. 21, 1306-1312.

19. Nowoshilow S et al. 2018 The axolotl genome and the evolution of key tissue formation regulators. Nature 554, 50-55.

20. Doyle JM, Siegmund G, Ruhl JD, Eo SH, Hale MC, Marra NJ, Waser PM, Dewoody JA. 2013 Microsatellite analyses across three diverse vertebrate transcriptomes. Genome 56, 407-414.

21. Mohlhenrich ER, Mueller RL. 2016 Genetic drift and mutational hazard in the evolution of salamander genomic gigantism. Evolution (N. Y). 70 , 2865-2878.

22. Che R, Sun Y, Wang R, Xu T. 2014 Transcriptomic analysis of endangered Chinese salamander: Identification of immune, sex and reproductionrelated genes and genetic markers. PLoS One 9, e87940.

23. Matsunami M, Kitano J, Kishida O, Michimae H, Miura T, Nishimura K. 2015 Transcriptome analysis of predator- and prey-induced phenotypic plasticity in the Hokkaido salamander (Hynobius retardatus). Mol. Ecol. 24, 3064-3076.

24. Abdullayev I, Kirkham M, Bjorklund SK, Simon A, Sandberg R. 2013 A reference transcriptome and inferred proteome for the salamander Notophthalmus viridescens. Exp. Cell Res. 319, 1187-1197.

25. Huang L, Li J, Anboukaria H, Luo Z, Zhao M, Wu H. 2016 Comparative transcriptome analyses of seven anurans reveal functions and adaptations of amphibian skin. Sci. Rep. 6, 24069.

26. Christenson MK et al. 2014 De novo assembly and analysis of the Northern leopard frog Rana pipiens transcriptome. J. Genomics 2, 141-9.

27. Amemiya CT et al. 2013 The African coelacanth genome provides insights into tetrapod evolution. Nature 496, 311-316.

28. Arnold K, Bordoli L, Kopp J, Schwede T. 2006 The SWISS-MODEL workspace: a web-based environment for protein structure homology modelling. Bioinformatics 22, 195-201.

29. Xu D, Zhang Y. $2012 \mathrm{Ab}$ initio protein structure assembly using continuous structure fragments and optimized knowledge-based force field. Proteins 80, 1715-1735.

30. Yang J, Yan R, Roy A, Xu D, Poisson J, Zhang Y. 2015 The I-TASSER 
Suite: protein structure and function prediction. Nat. Methods 12, 7-8.

31. Johansson J, Szyperski T, Curstedt T, Wüthrich K. 1994 The NMR structure of the pulmonary surfactant-associated polypeptide SP-C in an apolar solvent contains a valyl-rich alpha-helix. Biochemistry 33, 60156023.

32. Pyron RA, Wiens JJ. 2011 A large-scale phylogeny of Amphibia including over 2,800 species, and a revised classification of extant frogs, salamanders, and caecilians. Mol. Phylogenet. Evol. 61, 543-583. 